\title{
A Thermodynamic Theory of Economics
}

\author{
Final Post Review Version
}

\author{
John Bryant \\ VOCAT International Ltd, 10 Falconers Field, Harpenden, AL5 3ES, United Kingdom. \\ E-mail: john.bryant@vocat.co.uk
}

\begin{abstract}
An analogy between thermodynamic and economic theories and processes is developed further, following a previous paper published by the author in 1982. Economic equivalents are set out concerning the ideal gas equation, the gas constant, pressure, temperature, entropy, work done, specific heat and the $1^{\text {st }}$ and $2^{\text {nd }}$ Laws of Thermodynamics. The law of diminishing marginal utility was derived from thermodynamic first principles. Conditions are set out concerning the relationship of economic processes to entropic gain. A link between the Le Chatelier principle and economic processes is developed, culminating in a derivation of an equation similar in format to that of Cobb Douglas production function, but with an equilibrium constant and a disequilibrium function added to it. A trade cycle is constructed, utilising thermodynamic processes, and equations are derived for cycle efficiency, growth and entropy gain. A thermodynamic model of a money system is set out, and an attempt is made to relate interest rates, the rate of return, money demand and the velocity of circulation to entropy gain. Aspects concerning the measurement of economic value in thermodynamic terms are discussed.
\end{abstract}

Keywords: Thermodynamics, economics, Le Chatelier, entropy, utility, money, equilibrium, value, energy.

Publisher/Journal: This paper is the final post review version of a paper submitted to the International Journal of Exergy, published by Inderscience Publishers. Reference: Bryant, J. (2007) 'A thermodynamic theory of economics', Int. J. Exergy, Vol 4, No. 3, pp.302-337.

http://www.inderscience.com/browse/index.php?journalID $=135 \&$ year $=2007 \& v 0 l=4 \&$ issue $=3$

Biographical notes: John Bryant is managing director of VOCAT International Ltd, a company specialising in economic consultancy and research, and expert witness services. He has degrees in mechanical engineering and management science and his career appointments have included group economist and manager corporate planning for multi-national engineering corporations, and economist and investment analyst for a stock broking group. His research interests have centred on added value, the energy market and economic forecasting. He first became interested in the relationship between economic theory and the laws of thermodynamics in 1974, and has published several papers on the subject since that time.

\section{Introduction}

This paper develops further a theory that the author first investigated in 1974, culminating in a paper (Bryant, 1982) concerning the application of the laws of thermodynamics to economic theory. Since that time the boundaries of knowledge have expanded and as a result some of the ideas set down in that paper require significant revision. Others however appear to stand the test of time and further developments are added to here.

The nature of the subject requires significant proof for economists and scientists to accept that similarities between some thermodynamic and economic phenomena might imply more than just a passing analogy. They have however caught the attention of a growing band of researchers. Samuelson (1970) acknowledges that the relationships between pressure and volume in a thermodynamic system bear a striking similarity in terms of differentials to price and volume in an economic system and that the Le Chatelier Principle has various economic applications in the theory of constrained rationing and the theory of production. Pikler (1954) has highlighted the connections between temperature and the velocity of circulation of money, and Soddy (1934) has suggested that if Marx had substituted the word energy for labour he night have conceived an energy theory rather than a labour theory of value. Odum (1971) has developed the term "Embodied Energy" as totalling the energy input into a product, and more recently defined as Emergy (1998). Georgescu-Roegen (1979) has noted that economic systems exchange both energy and matter with their environment and are best represented as open thermodynamic systems. He argued that the entropy law was important. Lisman 
(1949), Candeal et al (1999) and Smith \& Foley (2002, 2004) have pointed to the similarities between utility and entropy. There exists a body of opinion therefore that acknowledges that links or analogies between thermodynamics and economics can be observed.

Others, however, highlight difficulties with economic and thermodynamic connections. Hammond (2004) believes that the two disciplines are quite different in character and application. Söllner (1997) suggests that there is no direct link between thermodynamic properties and the characteristics of economic systems, and that there has been a failure of most attempts to produce economically interesting results, although a breakthrough cannot be ruled out. Sousa \& Domingos (2005), while noting a relationship between utility and entropy believe that utility does not obey a conservation law as energy does, and equilibrium theory cannot be used to study irreversible processes. They argue that economic theory considers a circular flow between households and firms without considering the one-way flow that begins with resources and ends with waste. Patterson (1998), Costanza (1989) and Hannon (1989) all focus on the problem of trying to solve the 'mixed units' problem, commensurating dissimilar components.

At another level, the human race is a product of the environment and the biological systems from which it evolved, and the means by which it develops are likely to reflect the ways in which nature and energy systems operate. At the simplest level the fundamental principle guiding the kinetics of reactions between chemical substances is the Le Chatelier Principle which states: "If a change occurs in one of the factors under which a system is equilibrium, then the system will tend to adjust itself so as to annul as far as possible the effects of that change". Such reactions obey the laws of thermodynamics, in terms of heat production/consumption and the change in entropy arising. At a higher level of entity, living organisms are composed of complex chemical compounds, but made up chiefly of oxygen, hydrogen, nitrogen and carbon, all of which can exist as gases (the last with hydrogen or oxygen). Goldberg et al (1993-1999) have collated thermodynamic data on enzyme-catalysed reactions. Moving still further upwards, Schneider (1987) has pointed to Schrödinger's 'order from disorder' premise (1944), which was an attempt to link biology with the theorems of thermodynamics, whereby a living organism maintains itself stationary at a fairly high level of orderliness (low level of entropy) by continually sucking orderliness from its environment. Schneider and Kay (1992, 1995) state that life can be viewed as a far-from-equilibrium, dissipative structure, that maintains its local level of organisation at the expense of producing entropy in the environment. Successful species are those that funnel energy into their own production and reproduction and contribute to autocatalytic processes thereby increasing the total dissipation of the ecosystem.

While acknowledging the difficulties concerning the construction of analogues it is, nevertheless, not a far-flung idea to propose that some economic principles may have connections with and reflect some natural phenomena and the laws of thermodynamics.

\section{Stock and Flow Models}

\subsection{Development}

Economic systems can be represented as complex open interconnecting systems of stocks and flow processes carrying economic value, from resources through to production, distribution and consumption. The principle applies also to holdings in the economic system such as money and stock markets. Some processes involve multiple stock stages, and some can be virtually instantaneous before value is passed on to the next stage. Our model is likely to have the ability for price to go up or down, irrespective of the embodied productive content of any product in the system, however the latter may be measured, be it set against a monetary standard, or other yardsticks such as labour and emergy.

In the physical world, gases can absorb energy from a heat source with a higher temperature level, or by being compressed, raising their internal energy, resulting in a rise in temperature. To examine the characteristics of a gas in more detail recourse is made to the kinetic theory of gases.

It might be argued at this point, that while even a small volume of a gas contains very large numbers of molecules, homogenous and at first glance evenly dispersed (Avogadro's or Loschmidt's number indicates $6 x 10^{23}$ in just a thimbleful), some economic systems by contrast can be composed of just a few different items, and unevenly dispersed. Clearly relationships derived from a theory applied to a small system might be significantly clouded by the problems of small-sample statistics. But the counter arguments are that many economic systems and markets are quite large and the problems of small sample statistics would not then apply, and that economics take advantage of a human invention called money, a convenient commodity/medium of exchange with the property of linking non-homogenous economic factors together, so that they effectively work in a homogenous fashion. 
Real gases are imperfect, and their properties can diverge from a model of an ideal gas. Scientists take account of this fact by modifying the formulae arising from the notion of an ideal gas (such as the 'compressibility factor' and Van del Waal's equation) to enable thermodynamic principles to be applied more accurately; just as economists develop econometric and statistical models encompassing a number of factors to explain the variations in the real world that they see.

Imagine an ideal gas made up of a number $\mathbf{N}$ of molecules, which are perfectly elastic and are busy moving about colliding with each other exchanging kinetic energy. The relationship of the gas with the outside world at the system boundary is that it is contained in a volume $\mathbf{V}$ resulting in the gas exerting a pressure $\mathbf{P}$ on the walls of the system. If, through the application of heat, the gas molecules are made to vibrate and move about faster, they increase their rate of exchange of kinetic energy and the gas accumulates internal energy resulting in a temperature rise $\mathbf{T}$, with pressure and volume potentially increasing too. The relationship between the factors is given by the ideal gas equation:

$$
P V=N k T
$$

Where $\mathbf{k}$ is called the Boltzmann Constant (Ludwig Boltzmann 1844-1906).

An equation with a similar structure to equation (2.1) can be constructed for an economic system. Imagine a system involving a number $\mathbf{N}$ of 'monetary carriers or holders of value', equivalent in size to units of currency. Each carrier or holder can carry or hold a constant amount of embodied value k, which we will call the Monetary Constant, not dependent on price or volume, and usually given the numerical value 1 if a currency. For the time being, we put aside the problem of what standard the monetary constant $\mathbf{k}$ is measured against, i.e. energy, material content, labour manhours, gold or any entity that could be regarded as a medium of exchange. It is enough for the moment to assume that the result is acceptable to the parties in an economic system; otherwise they would not willingly trade with each other. The relationship of the system with the outside world is that the value held by carriers or holders can be exchanged for goods and services at the boundary of the system at price $\mathbf{P}$ and volume $\mathbf{V}$ over a period of time, according to an Index (or a degree of a scale) of Trading Value $\mathbf{T}$ with which they can do this over that period. If they could increase their index of trading value $\mathbf{T}$ over the same period, then the number of times the monetary units are re-cycled and used again goes up, and they could increase the value of exchange of goods over the period. Thus the relationship of the variables is given by the ideal economic equation:

$$
P V=N k T
$$

The index of trading value $\mathbf{T}$ has similarities with and is related to turnover, cost and added value, though the distinction is that while turnover, cost and added value can be defined in terms of a scale of value, rising or falling in an identical fashion to our index of trading value $\mathbf{T}$, they are not technically the same as $\mathbf{T}$, unless they are divided through by $\mathbf{N k}$.

The plot of price versus volume at Figure 1 indicates that for a given index of trading value $\mathbf{T}$ the carriers could carry more or less products with lower or higher prices, and a change in trading value index $\mathbf{T}$ can give rise to a change in volume $\mathbf{V}$, a change in price $\mathbf{P}$ or both.

It is important to stress that the index of trading value $\mathbf{T}$ so described here is one based on value, and not volume. If value, equal to price $\mathbf{P}$ multiplied by volume $\mathbf{V}$, can vary on one side of the equation, then on the other side some of the factors must be able to vary as well. Of these the embodied value of the monetary constant $\mathbf{k}$ that can be carried or held by a carrier, although inherently a value, is a nominal value and is deemed to be constant. It is the same whether trading occurs or not. A $£$ of currency is still a $£$ of currency. A share with a nominal value of $£ 1$ is still just that. A grain of wheat (if wheat were regarded as a possible means of exchange) is still a grain of wheat, whether or not it is traded. As it is possible that the number $\mathbf{N}$ of monetary carriers of value in a particular system configuration may be fixed (e.g. shares in issue), then the index of trading value $\mathbf{T}$ must be able to embody both changes in volume and price in order to make both sides of the equation compatible with one another. 


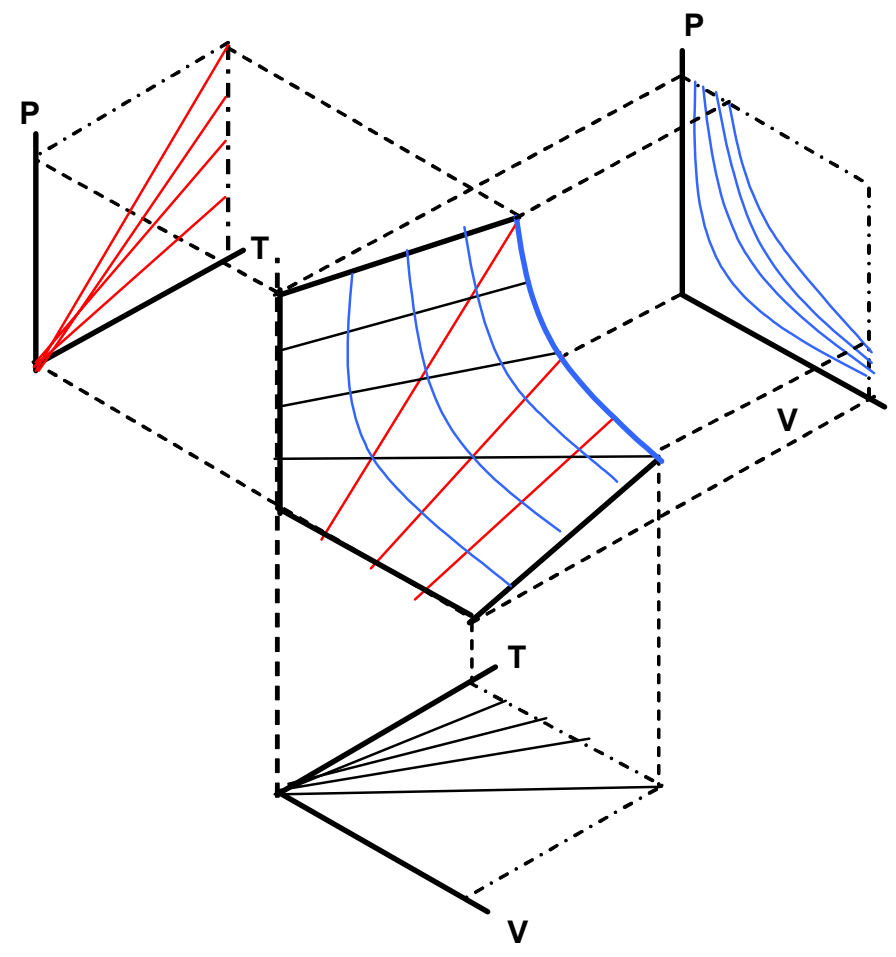

The structure of the ideal economic equation can be clarified further by reference to dimensional analysis. In a thermodynamic system, at the boundary, pressure $\mathbf{P}$ is measured by force $\mathbf{F}$ per unit of area (length $\mathbf{x}$ length $=\mathbf{L}^{2}$ ) on which it acts (i.e. $\mathbf{F} \times \mathbf{L}^{-2}$ ), and energy $\mathbf{J}$ is a product of force $\times$ distance moved (i.e. $\mathbf{F} \times \mathbf{L}$ ). Thus pressure $\mathbf{P}$ is equivalent to energy $\mathbf{J}$ per unit of volume (i.e. $\left.\mathbf{J} \times \mathbf{L}^{-3}\right)$. The Boltzmann constant $\mathbf{k}$ is defined as energy $(\mathbf{J})$ per molecule per degree of temperature (T). Therefore restating equation (2.1) in simplified dimensional terms we have:

$$
\left(\frac{J}{L^{3}}\right) \times\left(L^{3}\right)=N \times\left(\frac{J}{N T}\right) \times T
$$

Similarly for an economic system, at the boundary, in dimensional terms price $\mathbf{P}$ is measured as value $\mathbf{J}$ per volume $\mathbf{V}$, and the monetary constant $\mathbf{k}$ is measured as value $\mathbf{J}$ per carrier per index (or degree) of trading value T. Hence restating equation (2.2) we have:

$$
\left(\frac{J}{V}\right) \times(V)=N \times\left(\frac{J}{N T}\right) \times T
$$

Thus the formats of the ideal gas equation and the ideal economic equation outlined so far are similar, with a defined equivalence; pressure $\mathbf{P}$ with price per unit, volume $\mathbf{V}$ with units of output/consumption, the number of molecules of gas $\mathbf{N}$ with the number of monetary carriers or holders of value, temperature $\mathbf{T}$ with the index of trading value, and the Boltzmann constant $\mathbf{k}$ with the monetary constant per unit of carrier and index (degree) of trading value. The analogy suggests that value in an economic system might have some equivalence to heat content in a thermodynamic system.

\subsection{Simple Models}

We now turn to describe some simple models to illustrate the preceding principles. For the moment we leave out the thermodynamic analysis, which we will examine at a later section. 


\subsubsection{Money Stock}

The relationship of the money stock to output in an economy has been widely researched and, as noted earlier, Pikler (1954) has pointed to the connections between temperature and the velocity of circulation. The format of the money stock model is identical in structure to that developed in equation (2.2):

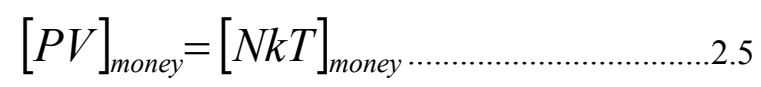

Where PV represents price level and volume output in an economy, $\mathbf{N}$ the number of notes, deposits, and other money instruments in circulation, $\mathbf{k}$ the nominal amount of value that each note is deemed to carry, and $\mathbf{T}$ is the velocity of circulation (equating to the index of trading value). By definition money is a homogenous commodity and moves in the opposite direction to other economic factors such as labour, materials and output. A change in the stock of money, not accompanied by an offsetting change in volume output, could result in changes in both the index of trading value and prices in an economy.

\subsubsection{Share Stock}

The share stock model is similar to that of money. If it is assumed that such shares are tradable on a market and that the number of shares in existence is constant, then the price and volume of shares traded PV per period of time is equal to the number of shares $\mathbf{N}$ in issue multiplied by the nominal value $\mathbf{k}$ (which is fixed) multiplied by the turnover rate $\mathbf{T}$ (equating to the index of trading value):

$$
[P V]_{\text {share }}=[N k T]_{\text {s }}
$$

The product Nk does not necessarily reflect the value of a corporation perceived by a market, as the latter is reflected in the index of trading value T. A change in future cash flows perceived by the market to arise from management decisions and corporate performance will reflect in a change in the index of trading value $\mathbf{T}$, which will in turn have an effect on trading volume $\mathbf{V}$ and price $\mathbf{P}$ thereof. A corporation issuing new shares can effect a change in the value of $\mathbf{N}$. The extent to which this reflects the perceived underlying future value of the corporation will determine any associated changes in the index of trading value $\mathbf{T}$, volume $\mathbf{V}$ and price $\mathbf{P}$.

\subsubsection{Production}

A production stock has items going into or out of it at the boundary over time, respectively arising from a previous production process, or proceeding on to a following process. Value $\mathbf{P V}$ comes into the stock, and leaves at the other end over a time interval. Carriers of value (monetary units) proceed in the opposite direction, each with a nominal amount $\mathbf{k}$. The number of carriers of value $\mathbf{N}$ available to the system is equal to the number of money units available to fund the operation. In a modern economy, a corporation without access to a supply of money (upfront, from a bank, from own resources or on credit) cannot carry out a process; enabling it to fund expenditure on materials and services while waiting for income to come in. The index of trading value $\mathbf{T}$ is therefore equal to the number of times the money units available to the system are turned over during the time interval during which $\mathbf{P V}$ crosses the boundary. Thus:

$$
[P V]_{p r o d}=[N k T]_{p r o d}
$$

In the equation, with the exception of $\mathbf{k}$, all of the other factors can vary. Price could go up or down for speculative reasons or if markets had declined resulting in a factory being left with stock having to be sold at knockdown prices. An appropriate change in $\mathbf{T}$ occurs to balance out a price change. Volume input and output might go up or down according to changes in requirements and stock-holding policy, and the number of money units $\mathbf{N}$ available to fund an operation can be influenced by bank credit policy. Efficient users of money are able to turn it over at a high rate with a consequent high level of $\mathbf{T}$.

A more simplified presentation of the above equation for a production process is to divide volume $\mathbf{V}$ by $\mathbf{N}$, to give a Specific Volume $\boldsymbol{v}$ per unit of currency available to the operation: 


$$
[P v]_{p r o d}=[k T]_{p}
$$

Thus for a unit of currency, a given level of specific output $\mathbf{P} \boldsymbol{v}$ is equated to the index of trading value $\mathbf{T}$; equivalent to turnover per unit of currency turned over.

Production processes are often grouped together or connected to one another in a flow process. The above principle still applies to throughput of output, wage and material costs per unit of currency used to fund the operation.

\subsubsection{Consumption}

The consumer model is similar in construction to the production one above. Thus PV represents income and expenditure, and $\mathbf{T}$ the number of time consumers turn over their holdings of monetary assets $\mathbf{N}$ in relation to income and expenditure.

$$
[P V]_{\text {cons }}=[N k T]_{c}
$$

As with production, a more simplified representation of the above equation for a consumption process is to divide volume $\mathbf{V}$ by $\mathbf{N}$, to give a Specific Volume $\boldsymbol{v}$ per unit of currency available to the operation:

$$
[P v]_{\text {cons }}=[k T]_{\text {con }}
$$

While economic theory often defines the consumer function as being the opposite of production, consuming the units produced by production, the author tends to the view that the consumer or personal sector too is a form of production function, since labour units are expended (deaths/proportion of lifetime work) in the production of new labour units (births and upbringing). A discussion of the structure is given at a later point in this paper.

\section{Thermodynamic Principles}

In this section we develop economic equivalents to the First and Second Laws of Thermodynamics, and examine the dynamics of the main processes encountered and as applied to an economic system.

\subsection{First Law of Thermodynamics}

The First Law is generally stated as:

$$
Q-W=\left(U_{2}-U_{1}\right)
$$

Where $\mathbf{Q}$ is the heat passing across the boundary of the system, $\mathbf{W}$ is the work done (or consumed) in the system and $\left(\mathbf{U}_{2}-\mathbf{U}_{1}\right)$ is the change in internal energy arising between states 1 and 2 , which is a function of the change in temperature. In differential form the equation is commonly written as:

$$
d Q-d W=d U
$$

In our economic system $\mathbf{d Q}$ is that value being put into or taken out of the system not represented by real output, such as a scarcity or abundance, or a write off of an asset, or an investor putting new money into an existing market that is not represented by the underlying productive value. It is not in the shape of embodied productive content and does not represent volume of throughput gained or lost. We shall call this the Entropic Value added or taken out.

The Work Done $\mathbf{d W}$ is defined as real embodied productive content added to or leaving a system by virtue of a volume change, and is written as $\mathbf{P d V}$ [or $\mathbf{P d v}$ if analysing on a specific volume basis per carrier of value, as per equation (2.10)]; being equal to price multiplied by change in volume, and would equate to part or all of real turnover, added value and costs. It does not incorporate value such as speculative or scarcity value. Thus real production output, labour consumption or consumption of raw materials would represent changes in work done. 
In our economic system we shall call the internal energy $\mathbf{U}$ 'Internal Value', the differential d $\mathbf{U}$ of which is equal to the addition of work done/consumed $\mathbf{d W}$ and entropic value $\mathbf{d Q}$ entering or leaving the system, depending upon the directions of flow. The concept of internal value is one that can incorporate both real productive content and entropic value, and has similarities to the concept of 'utility' developed by economists. This analogy will be developed at a later point in this paper. In our economic system the change in internal value $\mathbf{d U}$ is a function of the change in the index (or degree) of trading value $\mathbf{d T}$ which, from the chart at figure (2.1), is related to changes in price and volume.

\subsection{Second Law of Thermodynamics}

In a closed reversible thermodynamic system, there exists a property such that a change in its value between two states is equal to:

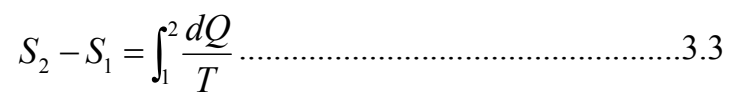

Or in differential form:

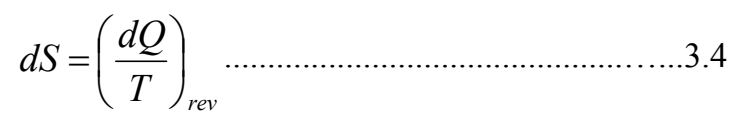

The property $\mathbf{S}$ of a physical system is called Entropy. In thermodynamics, entropy is a measure of the amount of energy in a physical system that cannot be used to do work. In statistical mechanics it is defined as a measure of the probability that a system would be in such a state, which is usually referred to as the "disorder" or "randomness" present in a system. Given that systems are not in general reversible then, following whatever means are applied to return a system to its starting point, the net change in cycle entropy is commonly stated as:

$$
\oint \frac{d Q}{T} \geq 0
$$

It is impossible to construct a system which will operate in a cycle, extract heat from a reservoir and do an equivalent amount of work on the surroundings. Entropy tends to rise.

By substitution of equation (3.4) into equation (3.2) and inserting the term for the work done $\mathbf{d W}=\mathbf{P d V}$ we have:

$$
T d S=d U+P d V
$$

Equation (3.6) sets out the general relations between the properties and, when integrated, gives the change in entropy occurring between any two equilibrium states, regardless of whether any particular process joining them is carried out reversibly or not.

In our economic system therefore, entropy change is defined as a measure of the amount of value per index of trading value that is not available in a particular economic process for conversion into real productive content and work done.

A series of economic processes is now examined to develop what these concepts mean in economic terms. The key relationships are illustrated in Figure 2. 
Figure 2 Price - volume relationships

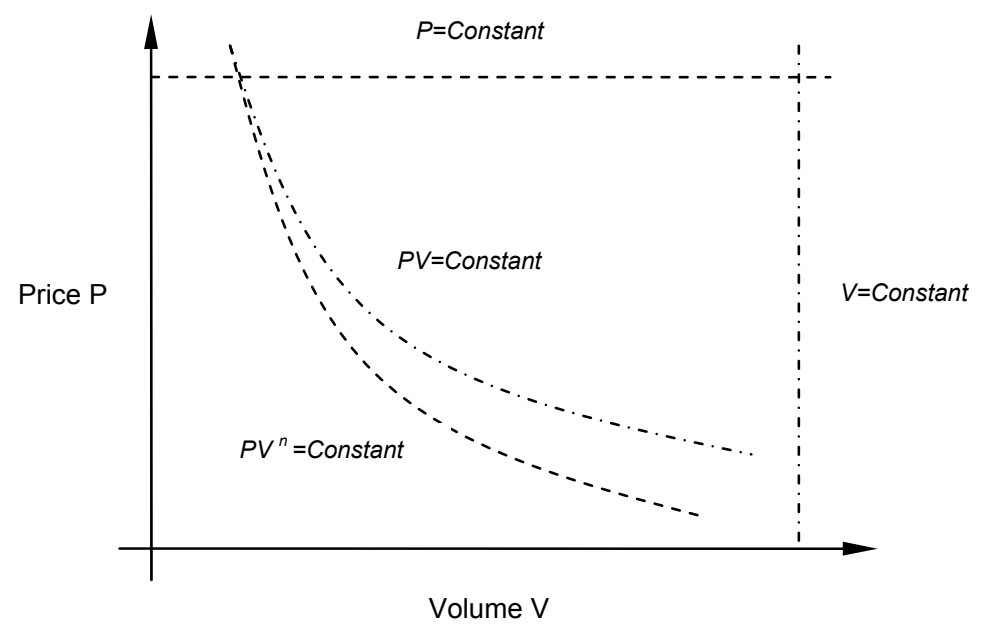

\subsection{Constant Volume}

By definition, a constant volume process is one involving no change in volume $\mathbf{V}$, and the work done $\mathbf{P d V}$ put in or taken out of the economic system is therefore zero. Thus entropic value dQ entering or leaving the system must be balanced by an equal change in the internal value $\mathbf{d U}$ of the system. Hence equations (3.2) and (3.6) become:

$$
d Q=d U=T d S
$$

Thus the change in internal value $\mathbf{d U}$ is then reflected as a change in entropy of the system $\mathbf{d S}$. By differentiating the ideal economic equation $\mathbf{P V}=\mathbf{N k T}$ we could write:

$$
P d V+V d P=N k d T
$$

And remembering in this case that volume output is constant, then:

$$
V d P=N k d T
$$

Hence by substituting in $\mathbf{P V}=\mathbf{N k T}$ again we have:

$$
\frac{d P}{P}=\frac{d T}{T}
$$

And

$$
\frac{P_{2}}{P_{1}}=\frac{T_{2}}{T_{1}}
$$

Thus the price of output in the process changes exactly in proportion to the change in the index of trading value dT arising from the input or output of entropic value $\mathbf{d Q}$ to and from the system. Nothing has been done to the items in the system, no work has been done; they are just perceived by the players in the system as having more or less value, by virtue of the entropic value $\mathbf{d Q}$ introduced or taken away. Economists might indicate that a change in price/value of this kind could arise from changes in scarcity or abundance.

Now in order to compute the change in entropy associated with this process, we have first to set out a relationship between the change in the internal value and the change in the index of trading value. We could write:

$$
d U=N C_{v} d T
$$


Where $\mathbf{C}_{\mathbf{v}}$ is a constant (for an 'ideal' economic system), which we shall call the Specific Value at constant volume. Thus the change in internal value per carrier goes up in proportion to the change in the index of trading value.

The thermodynamic analogy here is the specific heat at constant volume, being the heat required to raise the temperature of a unit of a gas system by one degree of a scale of temperature. The specific heat of a gas is commonly computed in thermodynamics terms by reference to either unit mass or quantity. The usual measure of the latter is per mole. For a monatomic ideal gas the specific heat at constant volume $\mathbf{C}_{\mathbf{v}}=\mathbf{( 3 / 2 )} \mathbf{N}_{\mathbf{A}} \mathbf{k}$, where $\mathbf{N}_{\mathbf{A}}$ is Avogadro's Number. Thus specific heat is measured as heat value relating to a multiple of numbers of molecules.

In this paper the specific value at constant volume $\mathbf{C}_{\mathbf{v}}$ in an economic system is definedas the amount of value $\mathbf{d U}$ required to be introduced to the internal value to change the index of trading value by $\mathbf{d T}$, per carrier of value (i.e.not $a$ multiple of units as with gases), but without any net change in volume in or out of the system. It is a measure of ability to store the entropic value that is introduced by $\mathbf{d Q}$. In economic terms utility has risen or declined, but nothing of substance has been added or taken away.

It might be supposed that the value $\mathbf{C}_{\mathbf{v}}$ for an economic process would be a constant. However, in gas systems, according to the kinetic theory of gases, the specific heat at constant volume is actually dependent upon the complexity of the gas molecules. A simple molecule requires less energy to increase its momentum and raise its temperature, than does a complex one, according to the number of 'degrees of freedom' - dimensional, rotational and vibrational energies (quantum mechanics introduces yet further degrees of freedom, those of electronic and nuclear). And in reverse, a complex molecule releases more energy for a given drop in temperature than does a simple molecule. The question therefore arises therefore as to whether such a variation is possible in an economic system.

The answer proposed in this paper is that such variation, if it occurs, is likely to depend on the 'complexity' of the carriers of value in terms of what they do and the time over which their value can be abstracted. For example, money in the form of cash clearly has value as a means of exchange, but has little other use beyond instantaneous conversion to and from goods and services. It might be deemed to have a short term value of $\mathbf{C}_{\mathbf{v}}$. By contrast, goods that are produced and consumed have value that can only be released over time. Last, humankind also places a value on goods with aesthetic properties that are rare and deemed to have value over a very long period. In economic terms 'degree of value' might be a better description of the property than 'degree of freedom'. Monetary examples of 'degrees of value' might be represented by cash (degree 1), versus gilts and income generating securities (degree 2) and gold (degree 3). While it is an open question as to whether a variation in $\mathbf{C}_{\mathbf{v}}$ might occur, the safe option is to allow for such a possibility in developing the analysis. Thus our specific value at constant volume $\mathbf{C}_{\mathbf{v}}$ might be deemed to be proportional to the embodied value of the monetary constant $\mathbf{k}$ of a given carrier of value, according to the 'degrees of value' attached thereto, and the value necessary to change the index of trading value by dT. Hence in our constant volume economic system we could write:

$$
C_{v}=\omega k
$$

Where $\boldsymbol{\omega}$ might be called the Value Capacity Coefficient.

By combining equations (3.4), (3.7), (3.11) and (3.12), the entropy change in the economic system is then written as:

$$
d S=\left(\frac{d Q}{T}\right)_{r e v}=\left(\frac{d U}{T}\right)_{r e v}=N C_{v}\left(\frac{d T}{T}\right)_{r e v}=\omega N k\left(\frac{d T}{T}\right)_{r e v}
$$

Thence by integrating we have (including for non-reversible systems):

$$
S_{2}-S_{1}=\omega N k \ln \left(\frac{T_{2}}{T_{1}}\right)
$$

And by substituting in equation (3.10) we have:

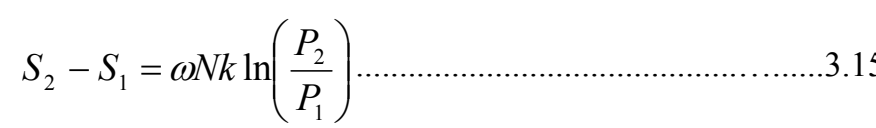


Thus stating the change in entropy in terms of the value capacity coefficient $\boldsymbol{\omega}$ and changes in the index of trading value and the price.

In differential form equations (3.14) and (3.15) can be written as:

$$
d S=\omega N k\left(\frac{d P}{P}\right)_{r e v}=\omega N k\left(\frac{d T}{T}\right)_{r e v}
$$

Thus entropy change in the constant volume process is proportional to the percent change in price or index of trading value.

\subsection{Constant Price}

This process is suitable for production or consumption processes where new units come into the system or go out the other end. By definition, a constant price process is one involving a change in volume, but no change in price. Work done is not therefore zero, and any entropic value $\mathbf{d Q}$ entering or leaving the system must equate to the work done $\mathbf{d W}$ plus the change in the internal value $\mathbf{d U}$ of the system. Hence equation (3.2) is stated as:

$$
d Q=d W+d U
$$

or

$$
d Q=d(P V)+d U
$$

Now in differential form, the ideal equation $\mathbf{P V}=\mathbf{N k T}$ can be written as:

$$
d(P V)=P d V+V d p=N k d T
$$

But since in this process price remains constant, VdP is zero, we can write:

$$
P d V=N k d T
$$

Hence by combining equations (3.11), (3.18) and (3.19):

$$
\begin{aligned}
& d Q=P d V+N C_{v} d T \\
& =N k d T+N C_{v} d T \\
& =N C_{p} d T
\end{aligned}
$$

Where $\mathbf{C}_{\mathbf{p}}=\left(\mathbf{C}_{\mathbf{v}}+\mathbf{k}\right)$ is a constant, which we shall call the Specific Value at constant price, being analogous to the specific heat at constant pressure in a thermodynamic system, in a similar manner to the constant volume process discussed above.

It will be recalled also from equation (3.12) that the specific value at constant volume using our value capacity coefficient was $\mathbf{C}_{\mathbf{v}}=\boldsymbol{\omega} \mathbf{k}$; thence we could write for a constant price process:

$$
\begin{aligned}
C_{p} & =\omega k+k \\
& =(\omega+1) k
\end{aligned}
$$

The higher value of the specific value at constant price, compared to that of the specific value at constant volume, recognises that in adding value to the internal value $\mathbf{U}$, volume movement of units takes place. Additional value has been stored, i.e. not only the entropic value $\mathbf{\omega k}$ (equation 3.16), but also real value $\mathbf{k}$ from production/consumption. 
Now by substituting the ideal equation $\mathbf{P V}=\mathbf{N k T}$ back into equation (3.19) and remembering that price is constant we have:

$$
\frac{d V}{V}=\frac{d T}{T}
$$

And

$$
\frac{V_{2}}{V_{1}}=\frac{T_{2}}{T_{1}}
$$

Thus the volume of input or output goes up exactly in proportion to the change in the index of trading value; which is what one might expect for a constant price process. A change in the index of trading value finds its way wholly into a change in volume, and not price.

Similarly by combining equations (3.4), (3.20) and (3.21), the entropy gain from the system is written as:

$$
d S=\left(\frac{d Q}{T}\right)_{r e v}=N C_{p}\left(\frac{d T}{T}\right)_{r e v}=N k(\omega+1)\left(\frac{d T}{T}\right)_{r e v} \ldots \ldots \ldots . .3 .24
$$

Thence by integrating we have for a constant price process (including for non-reversible systems):

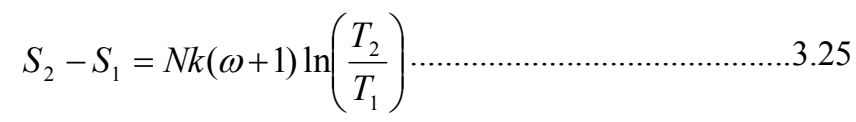

And by substituting in equation (3.23) we have:

$$
S_{2}-S_{1}=N k(\omega+1) \ln \left(\frac{V_{2}}{V_{1}}\right)
$$

Thus stating the change in entropy for the constant price process in terms of the change in the index of trading value, and in terms of the associated change in volume.

\subsection{Iso-trading}

As its name suggests, the iso-trading model is one where no change in the index of trading value occurs, that is $\mathbf{d T}=\mathbf{0}$. The equivalent thermodynamic process is the isothermal case where temperature change is zero. In mathematical terms we can write:

$$
P V=C
$$

Where $\mathrm{C}$ is a constant and price varies inversely with volume. This formula has common usage in standard textbooks on economic theory, and the shape of the curve is depicted at figures (2.1) and (3.1) of this paper.

Clearly the formula does not have use in stocks where changes in effective trading $\mathbf{T}$ takes place, and because economic processes are mostly one-way, it is not possible to change one unit of volume with one price into another unit with another price, except via the process of conversion - that is the production process when inputs are consumed and outputs produced, which we will examine later in this paper. Outside conversion/production processes, however, the model may also have use in the theory of consumer choice. In our model, since $\mathbf{T}$ is constant, there is no change in Internal Value $\mathbf{d U}$, and therefore any change in work done $\mathbf{d W}$ is reflected in a change in entropic value $\mathbf{d Q}$. Thus:

$$
d Q=d W=P d V
$$

And from the ideal equation $\mathbf{P V}=\mathbf{N k T}$ in differential form:

$$
P d V+V d P=0
$$

Hence: 


$$
\frac{d P}{P}=-\frac{d V}{V} .
$$

Indicating, as would be expected, that change in price is equal and opposite to a change in volume.

By substituting equation (3.28) into equation (3.4) for the entropy change we have:

$$
d S=\left(\frac{d Q}{T}\right)_{\text {rev }}=\frac{1}{T}(P d V)_{r e v}
$$

And by substituting in $\mathbf{P V}=\mathbf{N k T}$, we have:

$$
d S=N k\left(\frac{d V}{V}\right)_{r e v}
$$

And

$$
d S=-N k\left(\frac{d P}{P}\right)_{\text {rev }}
$$

Hence by integrating:

$$
S_{2}-S_{1}=N k \ln \left(\frac{V_{2}}{V_{1}}\right)
$$

And:

$$
S_{2}-S_{1}=N k \ln \left(\frac{P_{1}}{P_{2}}\right)
$$

Thus we have a logarithmic relationship of entropy change with change in volume and an equal and opposite logarithmic relation with change in price.

\subsection{Entropic Change and Marginal Utility}

From the analyses of the constant volume, constant price and iso-trading processes so far highlighted, it is possible to investigate relationships between entropy change and utility theory. For example equation (3.30), the entropic gain for the iso-trading process, could be re-written as:

$$
\frac{d S}{d V}=N k\left(\frac{1}{V}\right)_{r e v}
$$

And by substituting in $\mathbf{P V}=\mathbf{N k T}$ we have:

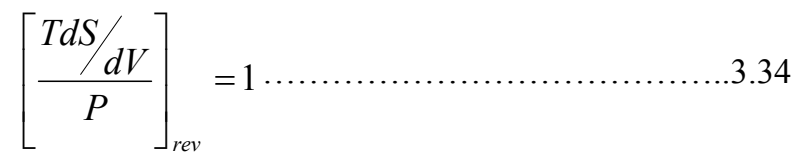

Thus the marginal change in entropic value TdS (equals dQ) with respect to volume change, divided by price, is equal to $\mathbf{1}$, which is a constant.

In economics, the simple utility theory postulates that at consumer equilibrium the marginal utility of one good divided by its price is equal to the marginal utility of another good divided by its price - the Law of Diminishing Marginal Utility. Thus the inference of the thermodynamic analysis of the above iso-trading process and equation (3.34) is that marginal utility might be related to marginal entropic value with respect to volume (TdS/dV). 
However this conclusion cannot be wholly derived from the other two processes, since utility is not just related to the entropic element, but is also related to the embodied productive content - both of which add to the internal value $\mathbf{U}$. But of course since for the iso-trading process there is by definition no change in internal value; changes in volume being met only by changes in price, a connection between change in entropic value TdS and change in utility might be held in this case.

Turning to the other two processes, in respect of the constant volume process, for $\mathbf{N}$ carriers of value we can write from equation (3.16):

$$
d S=\omega N k\left(\frac{d P}{P}\right)_{r e v}
$$

And substituting in $\mathbf{P V}=\mathbf{N k T}$, we have:

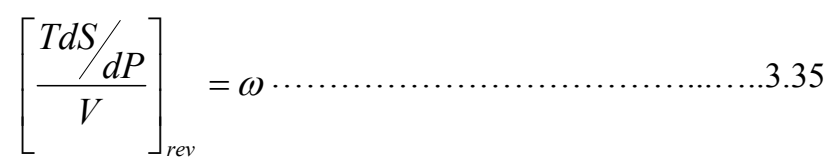

Which says that for a constant volume process the marginal entropic value with respect to change in price (TdS/dP), divided by volume, is equal to $\omega$, which is a constant.

Likewise, for the constant price process, for $\mathbf{N}$ carriers of value we can write from equation (3.26):

$$
d S=(\omega+1) N k\left(\frac{d V}{V}\right)_{r e v}
$$

And substituting in the ideal equation $\mathbf{P V}=\mathbf{N k T}$, we have:

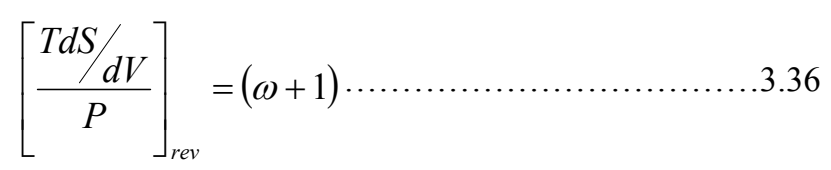

Thus the marginal entropic value with respect to volume change (TdS/dV) divided by price, is equal to a constant $(\omega+1)$, which is similar to the conclusion for the iso-trading process except that the constant is greater than 1 , (if $\omega>0$ ).

From all of the above analyses, the inference is that change in utility value, in an economic sense, may be related to change in internal value $\mathbf{d U}$, which is also a function of change in entropic value TdS and work done $\mathbf{d W}$, though the relationship depends upon the process examined. This conclusion is different that that obtained by Candeal (1999) and Smith \& Foley $(2002,2004)$ who related utility only to entropy.

\subsection{Polytropic Process}

A more general type of relationship of price against volume found in economic processes is of the form:

$$
P V^{n}=C
$$

Where $\mathbf{n}$ is a constant known as the elastic index. This is easily confirmed by differentiating the equation to give:

$$
\frac{d P}{P}=-n\left(\frac{d V}{V}\right)
$$

Supply and demand curves are often drawn to this formula with demand curves having a positive value of $\mathbf{n}$ and supply curves a negative value. In thermodynamics such processes are called Polytropic processes and we shall use the same term here. It will noted that when $\mathbf{n}=\mathbf{0}$ the relationship reduces to a constant price process, and when $\mathbf{n}=\infty$ it reduces to a constant volume one.

Now, referring back to our formula for the work done/released in producing or consuming output, we have: 


$$
W=\int_{1}^{2} P d V=\int_{1}^{2} \frac{C}{V^{n}} d V
$$

Thence by integration and substitution we get:

$$
W=\left(\frac{P_{2} V_{2}-P_{1} V_{1}}{1-n}\right)
$$

And by further substitution of the ideal equation $\mathbf{P V}=\mathbf{N k T}$ :

$$
W=\left(\frac{N k}{1-n}\right)\left(T_{2}-T_{1}\right)
$$

Substituting the above back into our equation for the First Law relating entropic value to work done and the change in internal value we get:

$$
Q-\left(\frac{N k}{1-n}\right)\left(T_{2}-T_{1}\right)=U_{2}-U_{1}
$$

And re-arranging and substituting in the equation for the internal value:

$$
\begin{aligned}
Q & =N C_{v}\left(T_{2}-T_{1}\right)+\left(\frac{N k}{1-n}\right)\left(T_{2}-T_{1}\right) \\
& =N k\left(\omega+\frac{1}{1-n}\right)\left(T_{2}-T_{1}\right) \ldots \ldots \ldots \ldots \ldots \ldots
\end{aligned}
$$

Finally we have an expression for the change in entropy:

$$
S_{2}-S_{1}=N k\left(\omega+\frac{1}{1-n}\right) \ln \left(\frac{T_{2}}{T_{1}}\right)
$$

This equation can also be re-stated in terms of changes in price and changes in volume, by substituting in $\mathbf{P V}=\mathbf{C}^{\mathbf{n}}$, although we will not clutter up the picture here. There are nevertheless three expressions relating volume, price and the index of trading value:

$$
\begin{aligned}
& \frac{P_{2}}{P_{1}}=\left(\frac{V_{1}}{V_{2}}\right)^{n} . \\
& \frac{T_{2}}{T_{1}}=\left(\frac{P_{2}}{P_{1}}\right)^{\frac{n-1}{n}} \\
& \frac{T_{2}}{T_{1}}=\left(\frac{V_{2}}{V_{1}}\right)^{1-n}
\end{aligned}
$$

\subsection{Isentropic Process}

An important special case of the Polytropic process is that of the Isentropic case, where entropy change is zero, with no entropic value $\mathbf{Q}$ entering or leaving the system. Thus, in differential form the work done $\mathbf{d W}$ is equal to the change in internal value $\mathbf{d U}$ :

$$
d W=-d U=-N C_{v} d T
$$

Substituting in $\mathbf{P d V}$ for $\mathbf{d W}$ and setting alongside the ideal equation $\mathbf{P V}=\mathbf{N k T}$ we have: 


$$
\begin{aligned}
& P d V=-N C_{v} d T \quad \text { (First Law) } \\
& N k d T=P d V+V d P \quad \text { (Ideal Equation) }
\end{aligned}
$$

Eliminating $\mathbf{d T}$ from these equations and re-arranging we obtain:

$$
0=\left(1+\frac{C_{v}}{k}\right) P d V+\left(\frac{C_{v}}{k}\right) V d P
$$

And since $\mathrm{C}_{\mathrm{p}}=\mathrm{C}_{\mathrm{v}}+\mathrm{k}$, this reduces to:

$$
0=C_{p} P d V+C_{v} V d P
$$

By writing $\mathrm{C}_{\mathrm{p}} / \mathrm{C}_{\mathrm{v}}=\gamma=(\omega+1) / \omega$ this then becomes:

And finally by integrating we get:

$$
\gamma \frac{d V}{V}+\frac{d P}{P}=0
$$

$$
P V^{\gamma}=C
$$

Which is another form of equation (3.38) for the Polytropic process, with the elastic index $\gamma=(\omega+1) / \omega$ being a function of the value capacity coefficient $\boldsymbol{\omega}$.

We can therefore substitute in $\boldsymbol{\gamma}$ for $\mathbf{n}$ to arrive at the isentropic relationships between volume, price and the index of trading:

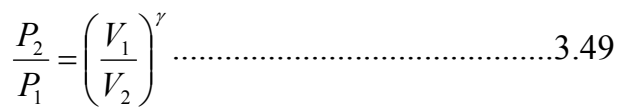

$$
\begin{aligned}
& \frac{T_{2}}{T_{1}}=\left(\frac{P_{2}}{P_{1}}\right)^{\frac{\gamma-1}{\gamma}} \\
& \frac{T_{2}}{T_{1}}=\left(\frac{V_{2}}{V_{1}}\right)^{1-\gamma}
\end{aligned}
$$

Since by definition there is no change in entropy in this process, all value changes to the internal value of the system involve only changes in real volume and embodied productive content, with no change in entropic value.

\subsection{Process Entropy}

The equations for entropic gain in the preceding processes examined all have a common form, and can all be derived from the entropic gain for the Polytropic process. It will be recalled from equation (3.43) that the expression for the change in entropy was derived as:

$$
S_{2}-S_{1}=N k\left(\omega+\frac{1}{1-n}\right) \ln \left(\frac{T_{2}}{T_{1}}\right)
$$

This can be re-stated as:

$$
S_{2}-S_{1}=N k \lambda \ln \left(\frac{T_{2}}{T_{1}}\right)
$$

Where

$$
\lambda=\left(\omega+\frac{1}{1-n}\right)
$$

May be called the Entropic Index. 
Hence the entropy change for a given process is related to the change in the index of trading value, and the value of the entropic index $\lambda$. The latter is a function only of the value capacity coefficient $\boldsymbol{\omega}$ and of the elastic index $\mathbf{n}$ of the process. Figure 3 shows how the entropic index varies with changes in the elastic index.

At the point where the elastic index $\mathbf{n}$ is equal to $(\boldsymbol{\omega}+\mathbf{1}) / \boldsymbol{\omega})$, the entropic index becomes zero with no gain in entropy occurring. This equates to the isentropic case (section 3.8). At the vertical line where the elastic index $\mathbf{n}$ is equal to 1 , we have the iso-trading process (section 3.5) where the entropy gain is not related to change in trading, but only to changes in price and volume. At the horizontal line where the entropic index is equal to $\omega$ we have the constant volume process (section 3.3). Last, we have that the entropic index $\lambda$ for a constant price process is equal to $(\boldsymbol{\omega}+1)($ Section 3.4), which implies an elastic index $\mathbf{n}$ equal to zero, with price not a function of volume.

Figure 3 Relationship between entropic index and elastic index

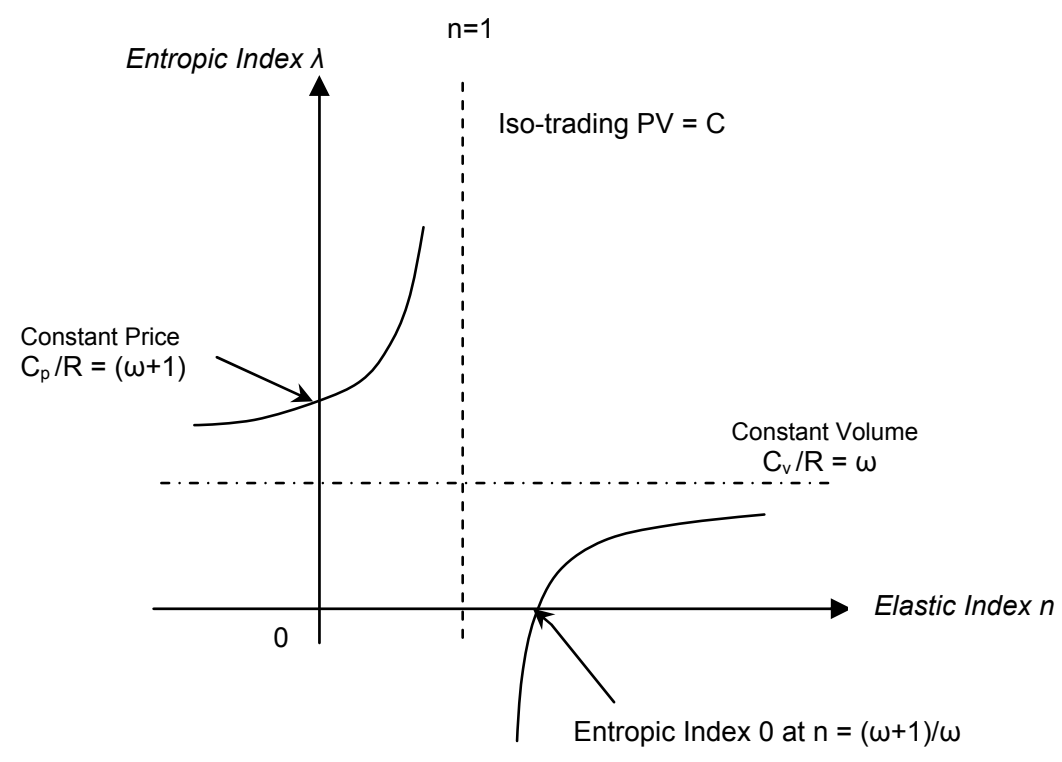

\section{Production and the Trade Cycle}

The stage has nearly been set where some of the concepts and relationships previously developed can be put together to form a model of an economic cycle. Figure 4 sets out the general format of a simplified capital - labour economy, with the corporate sector separated out from the personal sector. 


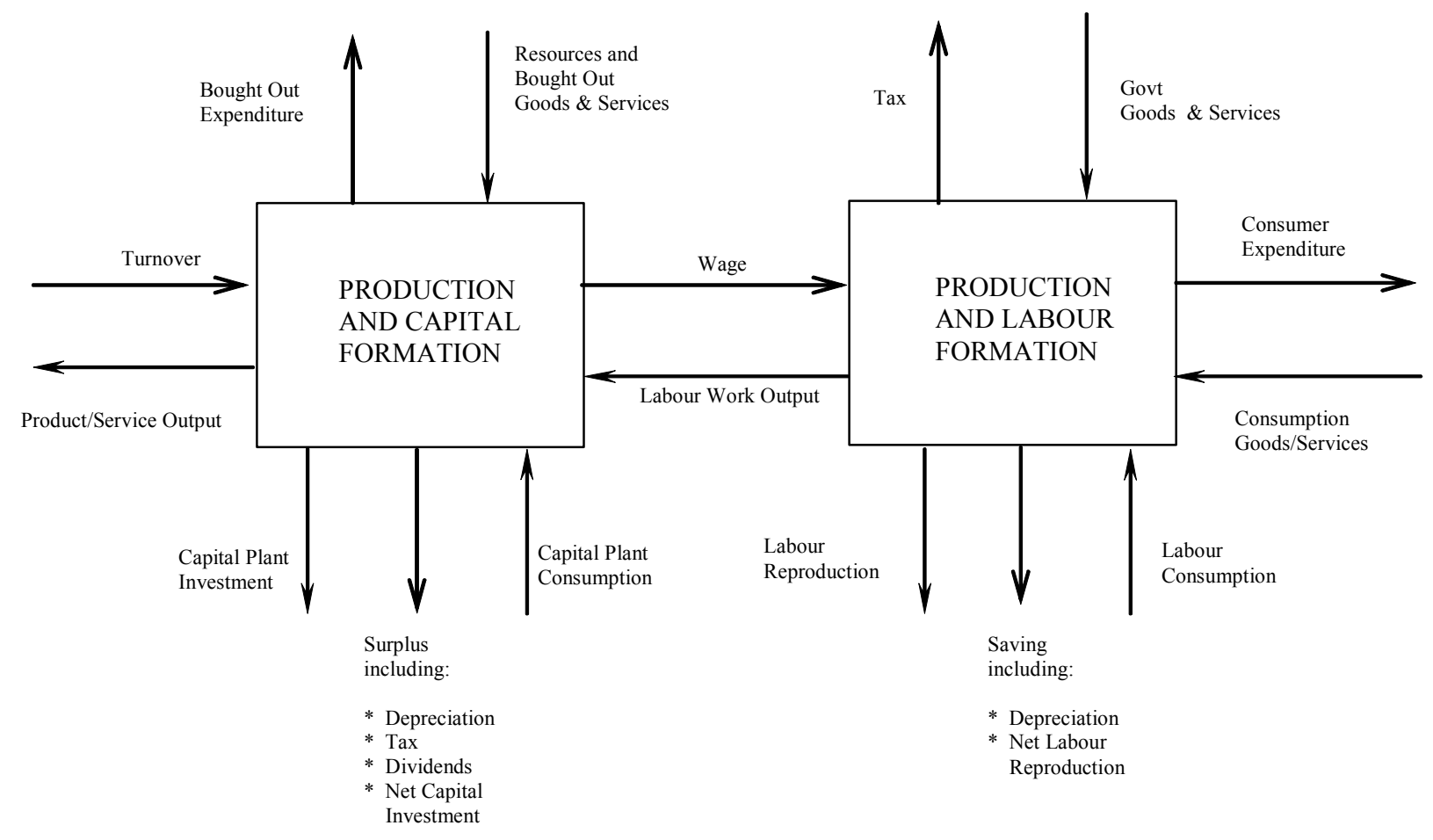

\subsection{Equilibrium \& Disequilibrium}

The theory developed to show the dynamic processes is based on the Le Chatelier Principle, stated at the beginning of this paper. It is not asserted that a system will attain equilibrium, only that it will continually seek to proceed to such a position. In fact the system will not work without being in a state of disequilibrium.

First, our analysis is restricted to an economic system involving only a specified, fixed process. By this is meant that, for example, to produce a product, specified amounts of capital (plant depreciation), labour (proportion of lifetime output) and materials are required, and no other combination, and which are brought together under a specified production process. If there is a scarcity such that a substitute is found, then the substitute is another product made by another process/system, and outside the dynamics of the system under analysis. Likewise if a different mix of inputs can be engineered by investment in plant and management, we are again discussing another system. It is only the dynamics of a fixed system that is being examined, and not feedback mechanisms to change the choice of system.

In gas/chemical combustion reactions such fixed arrangements are normal, there being only one configuration of inputs and outputs. For example, two molecules of carbon monoxide combust with one molecule of oxygen to form two molecules of carbon dioxide. There is no other combination. In a gas system with an inexact volume mixture, if a reaction proceeds so that some inputs are completely used up, there is likely to be some other inputs left over.

There is therefore a difference between human and chemical systems, in that humankind can continually modify its economic system in order to change the objectives and benefits - a complex feedback mechanism. Such mechanisms are outside the scope of this paper, but clearly could be the subject of future research.

Imagine a specific production system, whereby to form $\mathbf{x}$ units of a particular output product $\mathbf{G}$ (not including capital plant replacement/investment), requires a units of capital stock $\mathbf{K}$ (depreciation), $\mathbf{b}$ units of labour $\mathbf{L}$ (wage) and $\mathbf{c}$ units of resource B. $\mathbf{y}$ units of residue $\mathbf{D}$ are also produced. A surplus also likely occurs that is primarily used to purchase replacement capital stock and meet capital interest, tax and dividend payments. For the sake of analysis, we will assume this to be fixed in size at $\mathbf{z}$ units of capital stock $\mathbf{K}$. Any surplus after this constitutes potential for forward growth. We could write: 


$$
a K+b L+c B \Leftrightarrow x G+y D+z K
$$

Where the double arrow signifies that the process is not necessarily a complete one; it depends upon the actual relative concentrations of each. Thus if output $\mathbf{G}$ cannot be passed on to buyers from another system, if there is a labour shortage or a scarcity of materials from a late delivered stock or a resource depletion, or capital plant cannot be operated at higher level, then there will be a reduced economic incentive to promote the forward path in the system under consideration.

In respect of the personal sector, it might be postulated that a similar format could be considered; i.e. a units of labour $\mathbf{L}$ being consumed (proportion of lifetime value), resulting in $\mathbf{b}$ units of labour $\mathbf{L}$ (wage), which in turn can be spent on $\mathbf{x}$ units of labour reproduction $\mathbf{L}, \mathbf{y}$ units of capital assets $\mathbf{K}$ and $\mathbf{z}$ units of consumption $\mathbf{D}$. Consumers are generally much smaller entities than production units, and their choices are more diverse. It is possible that the number of units for each factor is not nearly as fixed as with the corporate production process, and the model may be more complex. People can choose to have more or less children, spend more or less on consumption (vital or less vital) and to invest more or less in fixed assets with varying depreciation rates. There is also a significant entropy factor to take into consideration in that people can choose to discard the productive content of some of their possessions earlier than their useful lives, resulting in an increase in entropy and the accumulation of some un-recyclable waste. The author believes that more research is relevant, particularly in the field of consumer choice and feed-back mechanisms, in order to build a better personal sector model.

In order to represent the work released by the consumption of capital, labour and resources and converted into product, we turn another thermodynamic property, known as the Helmholtz free energy function $\mathbf{F}$ (named after the German physicist Hermann von Helmholtz 1821 - 1894). This function is a common concept in thermodynamic analysis of chemical reactions, and expresses the total amount of energy which can be used up or released during a chemical reaction to equilibrium. It has the formula:

$$
\begin{gathered}
F=U-T S \\
d F=d U-S d T-T d S .
\end{gathered}
$$

A change in free energy is also equivalent to the change in Exergy of the system when proceeding to equilibrium. In economic terms the free energy might better be described as Free Value F, being the amount of useful value that can be used up or released during a reaction between inputs such as materials, labour, capital stock and energy, to produce output product. The change in free value $\mathbf{d F}$ is also related to the surplus/deficit that a corporation receives for its operation, after meeting its obligations.

Substituting in equations 3.2 and 3.7 for change in internal value dU into equation (4.2) we have:

$$
\begin{aligned}
& d F=T d S-d W-S d T-T d S \\
& d F=-(d W+S d T) \ldots \ldots \ldots \ldots \ldots \ldots
\end{aligned}
$$

Finally, we make the assumption that at the actual point of conversion, no change in the trading index $\mathbf{T}$ of either inputs or outputs occurs. Inputs are either just so before conversion, or instantaneously no longer there immediately after conversion; and likewise vice-versa for outputs. Thus for either inputs or outputs the equation reduces to:

$$
d F=-d W=-P d V
$$

Hence for a spontaneous reaction to take place to produce output work $\mathbf{d W}$, consumption of free value $\mathbf{d F}$ occurs. This process is similar to the iso-trading model at section (3.5) of this paper, where the index of trading value $\mathbf{T}$ was also constant. However, while in the iso-trading model changes in volume were met by changes in price, in our conversion / combustion process reduction in volume of inputs is met by an appropriate creation of product volume, with no change in price of either. By substituting in $\mathbf{P V}=\mathbf{N k T}$ we have: 


$$
d F=-N k T\left(\frac{d V}{V}\right)
$$

Hence the free value $\mathbf{F}$ available of either an input or output factor is:

$$
F=-N k T \ln (V)+F_{o}
$$

Where $\mathbf{F}_{\mathbf{0}}$ is the free value of a factor at its standard state position after our reaction has taken place. Although the factors of inputs and output are initially in arbitrary states, according to equation (4.1) however they have to combine/react in fixed proportions. Thus we write:

$$
a[F]_{K}+b[F]_{L}+c[F]_{B} \Leftrightarrow x[F]_{G}+y[F]_{D}+z[F]_{K}
$$

And substituting in from equation (4.6) we have:

Free value of outputs $=x\left[-N k T \ln (V)+F_{o}\right]_{G}+y\left[-N k T \ln (V)+F_{o}\right]_{D}+z\left[-N k T \ln (V)+F_{o}\right]_{K}$

And

Free value inputs $=a\left[-N k T \ln (V)+F_{o}\right]_{K}+b\left[-N k T \ln (V)+F_{o}\right]_{L}+c\left[-N k T \ln (V)+F_{o}\right]_{B}$

Thence the change in free value $\mathbf{\Delta} \mathbf{F}$ accompanying the reaction is the difference between these two:

$$
\Delta F=x\left[-N k T \ln (V)+F_{o}\right]_{G}+e t c-a\left[-N k T \ln (V)+F_{o}\right]_{K}-e t c
$$

In some economic systems, significant values are not ordinarily attached to a residue function and the ecological and environmental cost is assumed to be small. In other economic systems the function is substantial, with the cost of waste and/or environmental protection constituting a major deduction against potential benefits. Re-arranging equation (4.8) we have:

$$
\Delta F=\Delta F_{o}-N k T \ln \left[\frac{V_{G}^{x} V_{D}^{y} V_{K}^{z}}{V_{K}^{a} V_{L}^{b} V_{B}^{c}}\right]
$$

Where $\Delta \mathbf{F}_{\mathbf{0}}$ is the change in free value accompanying the reaction, when all the reactants and products are in their standard states. For mathematical convenience of basing everything on the product $\mathbf{G}$, equation (4.6) is re-written as:

$$
\Delta F / x=\left[\Delta F_{o} / x\right]-N k T \ln \left[\frac{V_{G} V_{D}^{\rho} V_{K}^{\tau}}{V_{K}^{\alpha} V_{L}^{\beta} V_{B}^{\delta}}\right]
$$

Where $\boldsymbol{\alpha}=\mathbf{a} / \mathbf{x}, \boldsymbol{\beta}=\mathbf{b} / \mathbf{x}, \boldsymbol{\delta}=\mathbf{c} / \mathbf{x} \boldsymbol{\rho}=\mathbf{y} / \mathbf{x}$, and $\boldsymbol{\tau}=\mathbf{z} / \mathbf{x}$.

Now when the reaction has stopped, the change in free value $\mathbf{\Delta} \mathbf{F}$ becomes zero, consequently from equation (4.10):

$$
\Delta F_{o} / x=N k T \ln \left[\frac{V_{G} V_{D}^{\rho} V_{K}^{\tau}}{V_{K}^{\alpha} V_{L}^{\beta} V_{B}^{\delta}}\right]_{e}
$$

Where the subscript $\mathbf{e}$ denotes the mix for the system at equilibrium. Since the standard free value change $\Delta \mathbf{F}_{\mathbf{0}}$ is the defined state of unit activity of the mix, it is apparent that $\Delta \mathbf{F}_{\mathbf{0}}$ must be constant, and it follows that the part of equation (4.8) contained in the brackets must be constant too. Thence: 


$$
\left[\frac{V_{G} V_{D}^{\rho} V_{K}^{\tau}}{V_{K}^{\alpha} V_{L}^{\beta} V_{B}^{\delta}}\right]_{e}=\psi
$$

Where $\boldsymbol{\Psi}$ may be called the Equilibrium Constant.

Finally by substituting back into (4.9) we have:

$$
\Delta F / x=-N k T \ln \left[\frac{V_{G} V_{D}^{\rho}}{V_{K}^{\alpha-\tau} V_{L}^{\beta} V_{B}^{\delta}}\right]+N k T \ln \psi
$$

And re-arranging:

$$
V_{G}=\psi\left[e^{-\Delta F / x N k T}\right]\left(V_{K}^{\alpha-\tau} V_{L}^{\beta} V_{B}^{\delta}\right)\left(V_{D}^{-\rho}\right)
$$

Which is an equation with similarities to the Cobb-Douglas production function, having input and output factors, but with an equilibrium constant and a free value disequilibrium function attached to it.

We thus return to the Le Chatelier Principle, a fundamental concept in physical, chemical and biological systems, but now defined for economic systems: "If a change occurs in one of the factors under which an economic system is in equilibrium, then the system will tend to adjust itself so as to annul as far as possible the effects of that change".

It can be seen from equation (4.14) that the forward path is favoured by a large free value function away from an equilibrium position, plentiful resources, coupled with a small waste function. Clearly, however, an economic system for which any of these components was lacking might at some point slow down, unless substitutes were found.

The assumption, in the above analysis, of a fixed level for part of the surplus to meet capital replacement and financial obligations ( $\mathbf{z}$ units of capital stock $\mathbf{K}$ ) does not have a strong foundation, since surpluses vary in the corporate sector a great deal. The principle of its effect on the equilibrium position for the purposes of promoting the forward path is however valid.

The dynamic nature of equation (4.14) becomes apparent when the condition of nil trading (constant index of trading value) is relaxed and the system is connected to all other adjacent systems in an economy. If one factor is used up - for example, product $\mathbf{G}$ is sold on to the next system - then the system produces more $\mathbf{G}$. Likewise as a resource $\mathbf{B}$ is used up, it is replaced from another system, which perceives demand for its product, and so the reaction goes on. We have derived an inter-reacting trading process, with free value continually being used up by one system and replaced by another. The limits of production will ultimately be set by demand, resource availability, and the ability of systems to recycle waste and discarded products. The nature of the processes outlined indicates that it is possible for business levels to go down as well as up in the long term.

Economic theory traditionally sets out a two-sided system with producers on one side and consumers on the other, the process being circular in nature. The equilibrium process described above, while undoubtedly incorporating such a circular process also has a linear dimension, converting resources into products, many of which cannot be re-cycled usefully back to the ecological system. In this model consumers are also producers. They invest in and bring up families who grow up and become part of the production cycle.

\subsection{The Business Cycle}

Physicists and engineers commonly describe the dynamics and efficiencies of a gas system in terms of a thermodynamic cycle where, following a compression process, reactants of air and fuel are brought together and ignited to give off heat, enabling the gases produced to expand and generate work in excess of that required for compression. Similarly, for an economic system, reactants of economic input are consumed and the result transformed into new product output. The system uses any excesses generated to procure replacements for factors used up, and any residue/deficit is then turned to future growth/decline. 
A number of cycles have been devised in thermodynamic theory to describe the dynamics and efficiencies of systems, but that devised by the French physicist Sadi Carnot (1837-94) is recognised to have the maximum theoretical efficiency that can be obtained. The cycle is made up of two Isothermal (Iso-trading) processes and two isentropic processes, as at Figure 5.

Figure 5 Carnot cycle
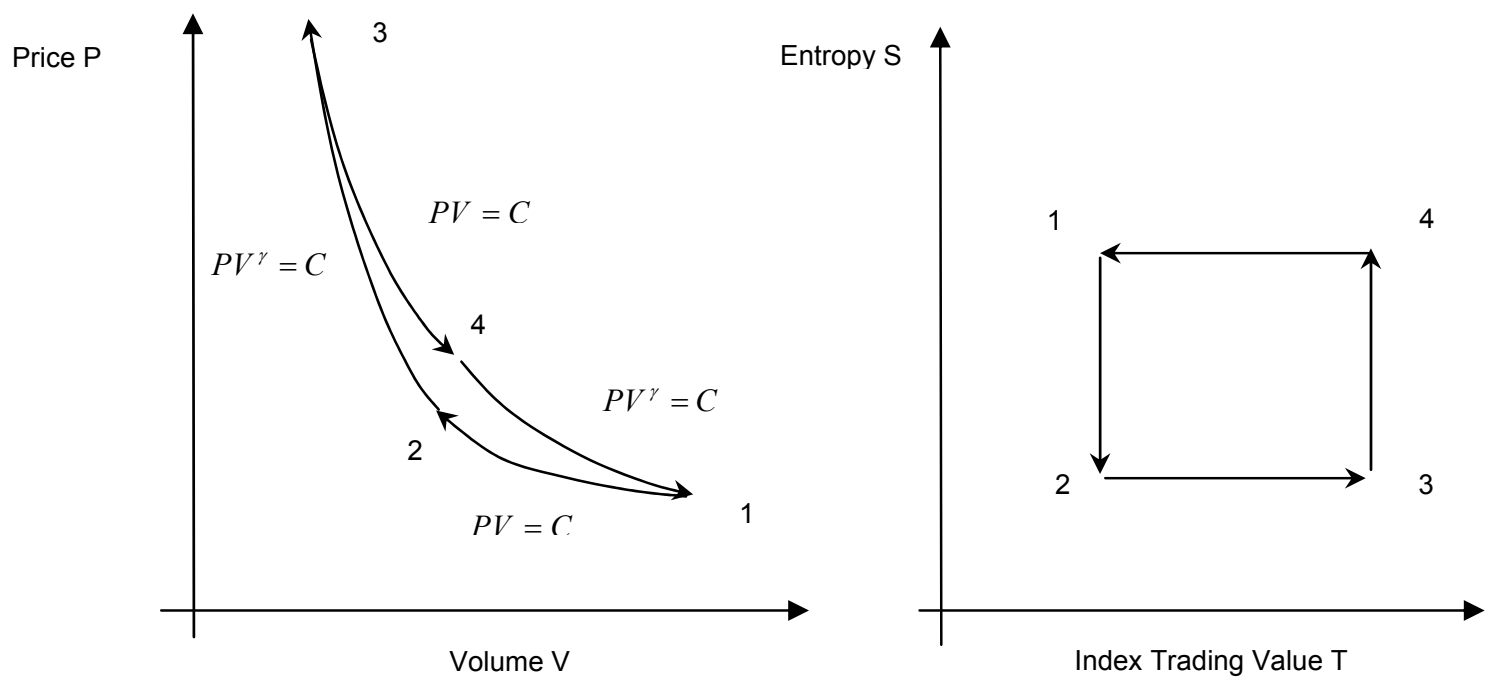

In the cycle, inputs enter at process 1-2, and are compressed at process 2-3. In process 3-4 they combust and acquire heat value, and at process 4-1 they expand. For a number of reasons, but chiefly because the area inside the P-V diagram is very small, implying little work done, the cycle is not thought to be applicable to economic systems. Other cycles that have been developed include the Otto cycle (Nikolaus Otto 1832-91), and the Rankine cycle (William Rankine 1820-72).

\subsection{Joule Cycle}

To overcome the problems posed by the Carnot cycle, a more practical cycle to use may be the Joule Cycle [named after James Joule 1818-89]. In the Joule cycle, constant pressure processes replace the isothermal processes of the Carnot cycle. Our economic model therefore now comprises two constant price and two isentropic processes. Figure 6 illustrates the shape of the cycle:

Figure $6 \quad$ Joule cycle
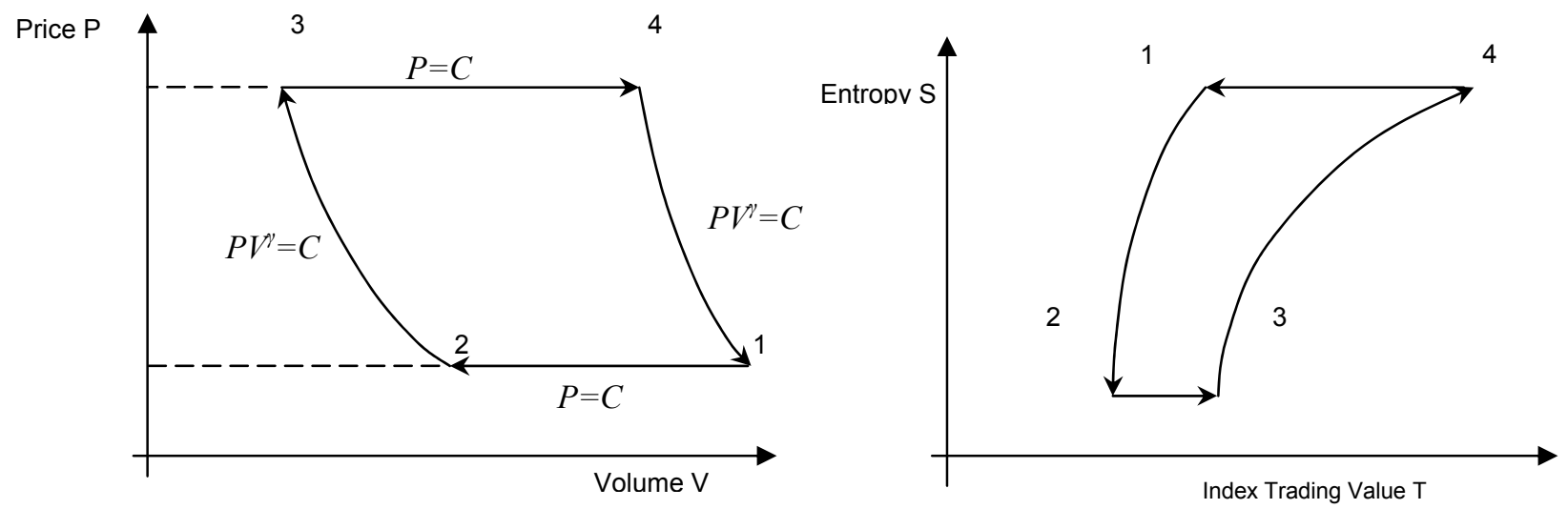
For a pure corporate/capital economy system, the cycle proposed is as follows:

(1-2) Labour output and materials are inputted. This process is assumed to utilise a constant price process. Opposite monetary flows of wages and expenditure on materials occur.

(2-3) Capital plant is consumed with the above input. This process is assumed to be isentropic, $\Delta \mathbf{W}=\Delta \mathbf{U}$, with no entropic value gain/loss. No cash transfer occurs as capital plant depreciates.

(3-4) Output of goods occurs. This process is assumed to be at constant price. Opposite monetary flows of sales/turnover occurs.

(4-1) A profit surplus/deficit occurs. This process is assumed to be isentropic, $\Delta \mathbf{W}=\boldsymbol{\Delta} \mathbf{U}$, with no entropic value gain/loss.

For a personal sector/labour economy system, the cycle proposed is as follows:

(1-2) Consumption of consumer goods occurs. This process is assumed to utilise a constant price process. Opposite monetary flows of consumer expenditure occurs.

(2-3) Labour is consumed (actually in the corporate sector, but here separated out). This process is assumed to be isentropic, $\Delta \mathbf{W}=\Delta \mathbf{U}$, with no entropic value gain/loss.

(3-4) Labour output occurs. This process is assumed to be at constant price. Opposite flows of wages occur.

(4-1) Labour reproduction occurs. This process is assumed to be isentropic, $\Delta \mathbf{W}=\boldsymbol{\Delta} \mathbf{U}$, with no entropic value gain/loss.

Rather obviously, a labour intensive economic system is likely to involve more of the latter system that the former, and vice-versa for a capital-intensive system, and grossing-up of individual systems to a macro-economic system will thus produce a mixed cycle, though the analysis of cycle efficiency criteria and other aspects remains the same.

For an economic system where residue D constitutes a cost factor with ecological and environmental implications, account of this could be made by adding a cost to process (1-2), increased capital consumption at process (2-3) or a tax and profit deduction at process (4-1).

In most economic systems, because of the nature of the specific processes and technology used, significant parts of added value are subcontracted out via bought-out materials and services, to improve efficiency. Once the latter have been inputted, the systems then add value to produce output. The effects of these are shown diagrammatically at Figure 7 - [processes (1-1a) and (3a-4)]:

We now examine a series of efficiency measures.

Figure $7 \quad$ Subcontract added value and the Joule cycle
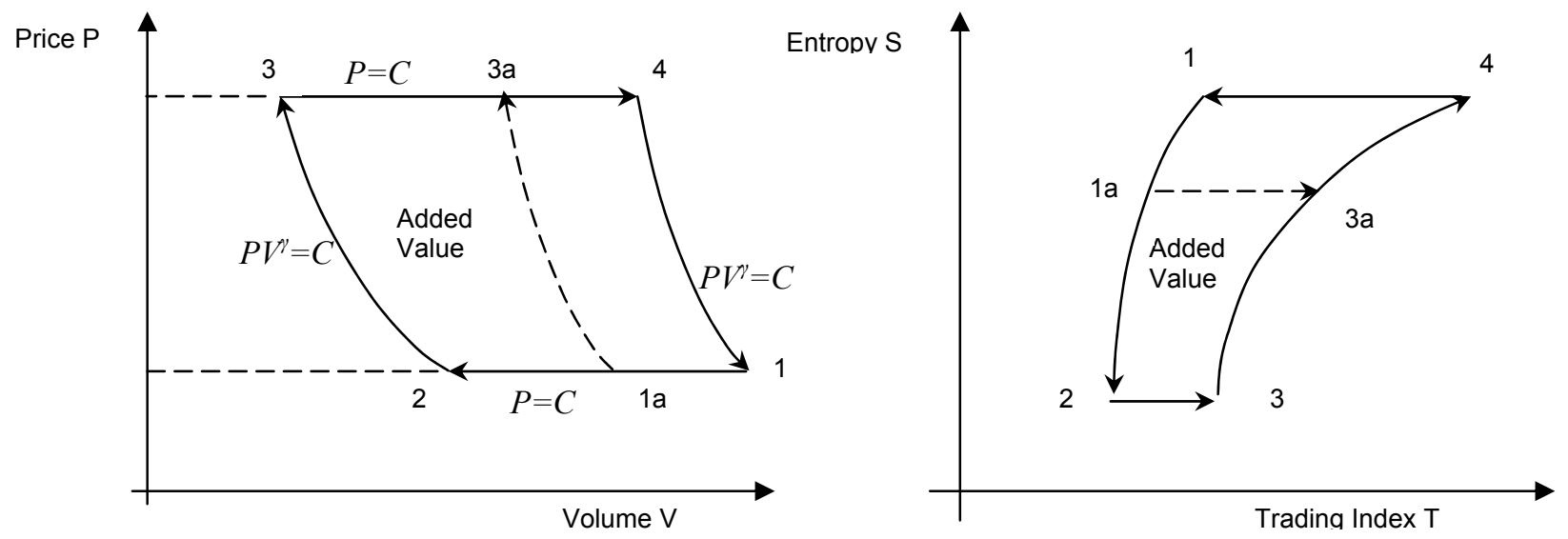

\subsubsection{Cycle Efficiency}

The efficiency of the cycles can be defined in a variety of ways but that known as the Overall Cycle Efficiency $\boldsymbol{\eta}$ is the most common. It is defined as work output less work input all divided by total output value: 


$$
\eta=\frac{W_{41}-W_{23}}{Q_{34}}
$$

And by substituting in for constant price and isentropic processes we get:

$$
\eta=\frac{-C_{p}\left(T_{3}-T_{2}\right)-C_{p}\left(T_{1}-T_{4}\right)}{C_{p}\left(T_{4}-T_{3}\right)} \ldots \ldots \ldots . . .17
$$

Now from fig (4.3) it can be seen that $\mathbf{P}_{3}=\mathbf{P}_{4}$ and $\mathbf{P}_{1}=\mathbf{P}_{2}$. Thus we can write:

$$
\frac{P_{3}}{P_{2}}=\frac{P_{4}}{P_{1}}=\mu
$$

Where $\boldsymbol{\mu}$ is the price gain from input to output [a mark-up on costs]. By making substitutions from equation (3.50) of this paper for the isentropic process, it can be proved that the overall efficiency of the cycle is given by the equation:

$$
\eta=1-\left(\frac{1}{\mu}\right)^{\frac{\gamma-1}{\gamma}}
$$

Thus the overall efficiency is governed by the price gain achievable, and the isentropic elastic index $\gamma$. Figure 8 shows the relationship to price gain:

Figure 8 Cycle efficiency and price gain

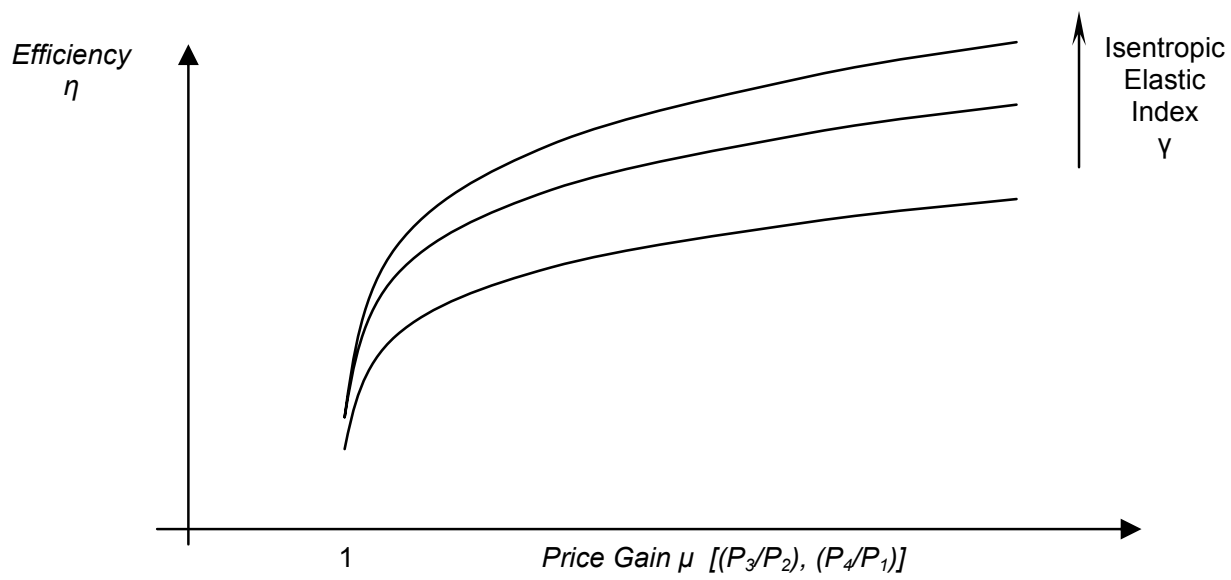

\subsubsection{Growth Factor}

In an economic cycle, overall cycle efficiency is not the only criteria to be considered. Attention needs also to be focussed also on the net work output, that is: (Work out - Work in) as a fraction of the Work in, which could be called the Growth Factor since, in the corporate sector this would be equal to:

\section{(Profit less capital consumption) / Capital consumption}

And similarly in the personal sector:

\section{(Labour reproduction - labour consumption) / Labour consumption}

Such a criterion would measure the extent to which a system is able to abstract value to enable it to replace and increase its productive resources. In algebraic terms the Growth Factor $\varphi$ is equal to: 


$$
\varphi=\frac{W_{23}-W_{41}}{W_{41}}
$$

And, by a similar process of algebraic manipulation to that used to derive the overall cycle efficiency $\boldsymbol{\eta}$, it can be proved that:

$$
\varphi=\left(\frac{T_{4}}{T_{2}}\right)\left(\frac{1}{\mu}\right)^{\frac{\gamma-1}{\gamma}}-1
$$

Thus the Growth Factor $\varphi$ is a function of the price gain $\boldsymbol{\mu}$ from input to output, the isentropic elastic index $\gamma$, and the overall cycle index of trading value gain $\left(\mathbf{T}_{4} / \mathbf{T}_{2}\right)$, from input to output, the latter being a function of the structure of the system. A vertically integrated cycle is likely to have a high value of $\left(\mathbf{T}_{\mathbf{4}} / \mathbf{T}_{\mathbf{2}}\right)$. Figure 9 shows the relationship of the Growth Factor to price gain:

It will be noted that $\varphi$ varies in an inverse way to the overall cycle efficiency.

By combining equations (4.18) and (4.19) the two criteria are related in the form:

$$
(\varphi+1)=\left(\frac{T_{4}}{T_{2}}\right)(1-\eta)
$$

Figure 9 Growth factor and price gain

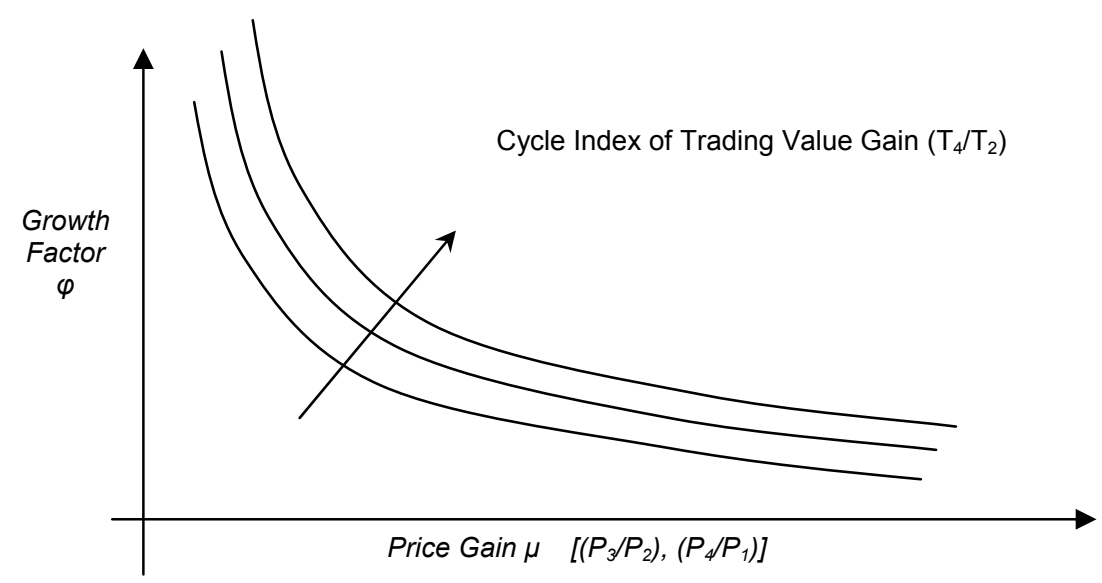

There is therefore a trade-off of overall cycle efficiency against improvements in growth and the degree of vertical integration $\left(\mathbf{T}_{4} / \mathbf{T}_{2}\right)$. The effect of this is illustrated at Figure 10:

Figure $10 \quad$ Growth factor and cycle efficiency

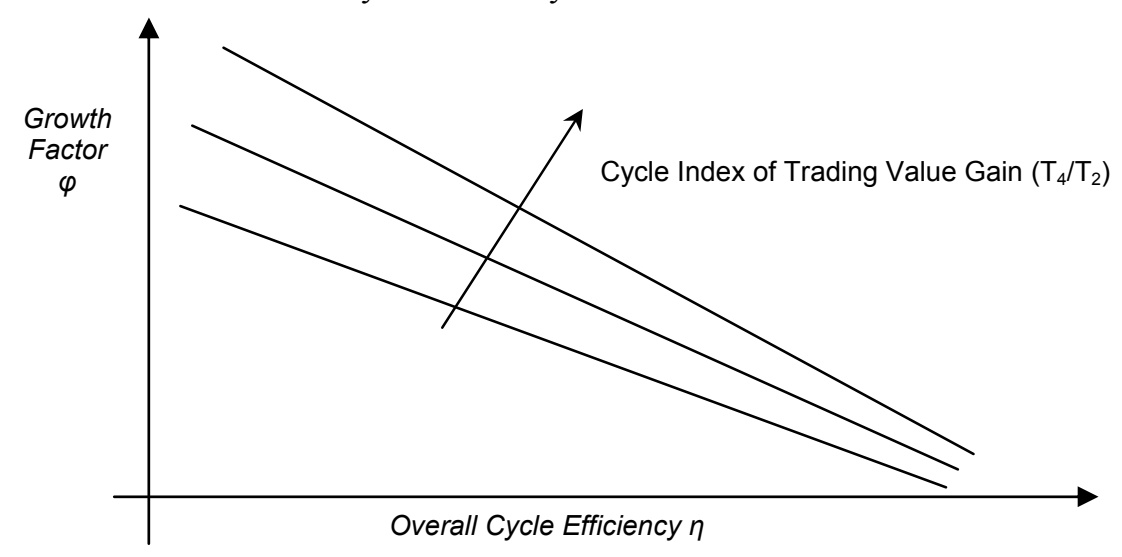




\subsubsection{Entropy Gain}

Finally, for the Joule Cycle, we can calculate the entropy gain. Since there is no change in entropy at processes 2-3 and 4-1 (they are isentropic), entropy change occurs only at processes 3-4 and 1-2. Thus the entropy change for the cycle is given as:

$$
\Delta S_{\text {cycle }}=\left(S_{4}-S_{3}\right)+\left(S_{2}-S_{1}\right)
$$

Substituting in for constant price processes for entropy gain (equation (3.25) we have:

$$
\Delta S_{\text {cycle }}=N k(\omega+1) \ln \left(\frac{T_{4}}{T_{3}}\right)+N k(\omega+1) \ln \left(\frac{T_{2}}{T_{1}}\right)
$$

And by substituting in equation (3.50) for the isentropic relationships and remembering that

We have:

$$
\frac{P_{3}}{P_{2}}=\frac{P_{4}}{P_{1}}=\mu
$$

$$
\Delta S_{\text {cycle }}=N k(\omega+1) \ln \left(\frac{T_{4}}{T_{2}}\right)\left(\frac{1}{\mu}\right)^{\frac{\gamma-1}{\gamma}}-N k(\omega+1) \ln \left(\frac{T_{4}}{T_{2}}\right)\left(\frac{1}{\mu}\right)^{\frac{\gamma-1}{\gamma}}=0
$$

Thus the entropy gain at one part of the cycle is wholly retrieved at the other, and the Joule Cycle is therefore reversible.

The real world, however, is one where inflation and a state of irreversibility is the norm. The isentropic processes (4-1) and (2-3) therefore become polytropic in nature and are replaced with $\mathbf{P} \mathbf{V}^{\mathbf{n}}=\mathbf{C}$. As before we summate the net entropy change for the cycle, which this time becomes:

$$
\Delta S_{\text {cycle }}=\left(S_{2}-S_{1}\right)+\left(S_{3}-S_{2}\right)+\left(S_{4}-S_{3}\right)+\left(S_{1}-S_{4}\right)
$$

And substituting for each process:

$$
\Delta S_{c y c l e}=N k(\omega+1) \ln \left(\frac{T_{2}}{T_{1}}\right)+N k\left(\omega+\frac{1}{1-n}\right) \ln \left(\frac{T_{3}}{T_{2}}\right)+N k(\omega+1) \ln \left(\frac{T_{4}}{T_{3}}\right)+N k\left(\omega+\frac{1}{1-n}\right) \ln \left(\frac{T_{1}}{T_{4}}\right)
$$

Which, after accounting for all four terms, reduces to:

$$
\Delta S_{\text {cycle }}=\left(\frac{n}{1-n}\right) N k \ln \left(\frac{T_{1}}{T_{2}}\right)\left(\frac{T_{3}}{T_{4}}\right)
$$

And from equations (3.45) \& (3.46) we can then write:

$$
\Delta S_{\text {cycle }}=-N k \ln \left(\frac{P_{1}}{P_{2}} \frac{P_{3}}{P_{4}}\right)
$$

And

$$
\Delta S_{\text {cycle }}=n N k \ln \left(\frac{V_{1}}{V_{2}} \frac{V_{3}}{V_{4}}\right)
$$

Thus entropy change through the cycle is proportional to logarithmic changes in price and volume through the cycle. 


\section{MONEY}

It will be recalled from equation (2.10) that the ideal equation for a money system was given by:

$$
P V=N k T
$$

This is a re-statement of the general quantity theory of money $\mathrm{pY}=\mathrm{MV}$, where $\mathrm{p}$ is price level in an economic system, $\mathrm{Y}$ is output in volume terms, $\mathrm{M}$ is the quantity of money and $\mathrm{V}$ is the velocity of circulation. While the left-hand sides of the equations are comparable, the right-hand side requires additional clarification. When referring to a quantity of money an economist is really referring to a numerical amount multiplied by a nominal value ( $£ 1, \$ 1$ or whatever) and in equation (5.1) this equal to Nk. Thus to obtain an exact comparison with the quantity theory, equation (5.1) can be written as:

$$
P V=[N k] T
$$

where the velocity of circulation in a money system is equivalent to the index of trading value $\mathbf{T}$ in a thermodynamic system. To avoid any confusion concerning the use of algebraic symbols the quantity theory equation $p Y=M V$ is dispensed with in this paper.

A particular point to note with a monetary model is that the velocity of circulation, calculated as output in value terms divided by money supply, does carry a connotation of value too, since the nominal value $\mathbf{k}$ is unchanging. Thus if the number of notes or instruments in circulation remains constant, when output price $\mathbf{P}$ and output volume $\mathbf{V}$ are each changing in some fashion, then the changes in $\mathbf{P}$ and $\mathbf{V}$ are reflected in a change in the velocity of circulation $\mathbf{T}$. As pointed out all through this paper $\mathbf{T}$ therefore carries value as well as volume. This is not to say of course that the number of money instruments $\mathbf{N}$ necessarily remains the same. Thus there are four variables to consider, and in differential form equation (5.2) can be written as:

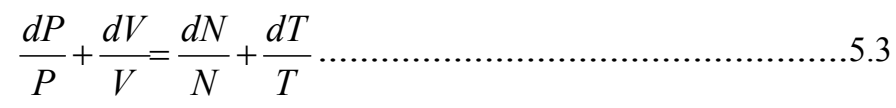

A possible means of simplifying the analysis is to divide output volume $\mathbf{V}$ by nominal money supply units $\mathbf{N}$. Let $\mathbf{v}=$ $\mathbf{V} / \mathbf{N}$, the Specific Volume, as per equations 2.8 and 2.10. While the specific volume $\mathbf{v}$ is not a constant, it will however incorporate technical trends, such as scalar changes in an economy and the amount of money required to fund it, changes in the type of monetary instruments in use, such as electronic money, and separate out the relative velocities of different kinds of money, from cash to securities. Thus equation (5.2) becomes:

$$
P v=k T
$$

And differentiating, and dividing by $[\mathbf{P v}=\mathbf{k T}]$ we have:

$$
\frac{d P}{P}+\frac{d v}{v}=\frac{d T}{T}
$$

Figure 11 illustrates the relationships between the three factors. 
Figure $11 \quad$ Velocity of circulation, price and specific volume
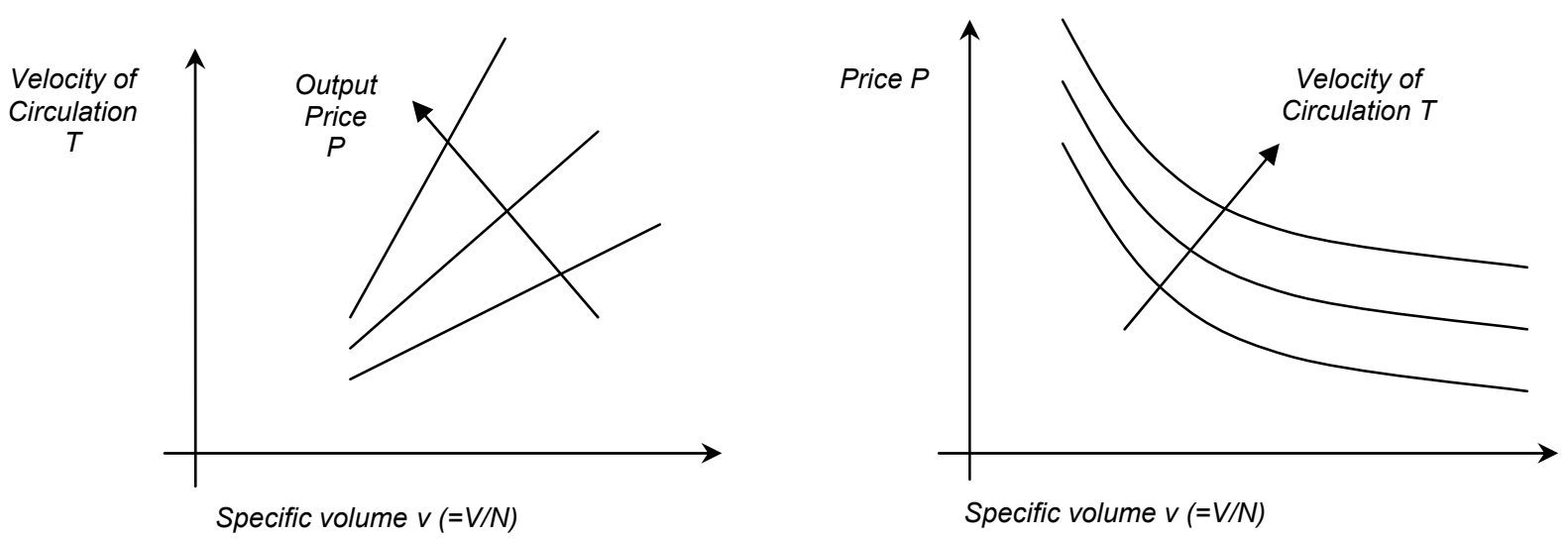

A change in velocity of circulation can arise either from a change in output price, or a change in the specific volume. And no change in the velocity of circulation will occur if a change in output price is balanced by an equivalent change in the specific volume.

Thus far, we have not derived any specific relationship between each of the variables, only that changes in one or more will be reflected by changes to the others. To deduce specific effects of particular changes to one or more variables, however, the relationships between the variables need to be defined.

For example, the Inventory Theoretic Model of money depicts money demand as being a function of output and a negative function of interest rates, and that changes in interest rates and money supply will therefore have an effect on investment and output. Accepted economic theory also takes into account such effects as the limitations on output and pressure on costs posed by constrictions in factors of production and international trade, though the latter effects are not owing to specific monetary factors.

It will be recalled at equations (3.11) and (3.12) of this paper that the concept of specific value $\mathbf{C}_{\mathbf{v}}$ was introduced, being a function of the degrees of value $\boldsymbol{\omega}$ that a carrier of value could carry $\left(\mathbf{C}_{\mathbf{v}}=\boldsymbol{\omega} \mathbf{k}\right)$. Thus $\mathbf{C}_{\mathbf{v}}$ represents the amount of value required to sustain a rise in the index of trading value (here the velocity of circulation), for a single carrier of value. To sustain a rise in the velocity of circulation, however, implies that all future value per carrier of value must also rise. This has similarities to the concept of discounted cash flow. Thus, for example, the net present value of a stream of income $\mathbf{k}$ per period per unit of currency, discounted at a rate of return or yield of $\sigma$ per period is equal to:

$$
\text { Net Present Value }=\sum_{t=1}^{N} \frac{k}{(1+\sigma)^{t}}
$$

For a discount period to $\infty$, this expression reduces to $[\mathbf{N P V}=\mathbf{k} / \boldsymbol{\sigma}]$. While most values of this kind do not of course involve a stream of income to $\infty$, the principle nevertheless remains valid.

We can suppose therefore that our Value Capacity Coefficient $\omega$ might be inversely related to some rate of return or yield $\mathbf{r}$ (not necessarily equal to $\sigma$ ), representative of the particular compass of carriers of value under consideration. Thus:

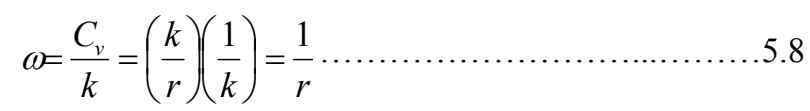

Again, we have not made any assumption concerning the specific relationships between each of the three variables $\mathbf{P}, \mathbf{v}$ and $\mathbf{T}$. While it is a matter of evidence as to what specific relationships are involved in a total economic system, we could get round this by making the assumption that the output price - specific volume relationship is of a polytropic form, $\mathbf{P v}^{\mathbf{n}}=\mathbf{C}$, that is, no special relationship such as constant price, constant volume or isentropic cases is assumed. On this basis, from equation (3.43), the differential form of any change in entropy may be presented as:

$$
d S=k\left(\omega+\frac{1}{1-n}\right) \frac{d T}{T}
$$


And substituting in from equation (5.8) we have:

$$
d S=k\left(\frac{1}{r}+\frac{1}{1-n}\right) \frac{d T}{T}
$$

It will be recalled also that for an isentropic process where $\mathbf{d S}=\mathbf{0}$, the expression in the brackets is equal to zero, and the value of $\mathbf{n}$ reduces to $\gamma$, where $\gamma=(\omega+1) / \omega$. Thus by substitution of $\mathbf{r}=\mathbf{1} / \boldsymbol{\omega}$, the value of $\mathbf{n}$ reduces to:

$$
n=\gamma=(1+r)
$$

Thus for an isentropic process the elastic index $\gamma$ is stated to be a function of the rate of return or yield $\mathbf{r}$.

Proceeding further and reverting back to the polytropic form, suppose that the rate of return is held at some value $\mathbf{i}$ other than $\mathbf{r}$, such that the elastic index $\mathbf{n}=(\mathbf{1}+\mathbf{i})$, then the differential expression for entropy change (5.10) reduces to:

$$
d S=\frac{k}{r}\left(\frac{i-r}{i}\right) \frac{d T}{T}
$$

Thus if the rate $\mathbf{i}$ is held below the rate of return $\mathbf{r}$, the expression becomes negative and entropy is abstracted from the system. Likewise if the rate $\mathbf{i}$ is above the rate of return $\mathbf{r}$, the expression becomes positive, with entropy being generated. Three differential expressions for the change in entropy can therefore be constructed, in terms of the changes in velocity of circulation $\mathbf{T}$, the specific volume $\mathbf{v}$ and the price $\mathbf{P}$ of output:

$$
\begin{aligned}
& d S=\frac{k}{r}\left(\frac{i-r}{i}\right) \frac{d T}{T} \ldots \ldots \ldots \ldots \ldots \ldots \ldots \ldots . . . . .13 \\
& d S=\frac{-k}{r}(i-r) \frac{d v}{v} \ldots \ldots \ldots \ldots \ldots \ldots \ldots \ldots \ldots .14 \\
& d S=\frac{k}{r}\left(\frac{(i-r)}{(1+i)}\right) \frac{d P}{P}
\end{aligned}
$$

For an isentropic process where $\mathbf{i}=\mathbf{r}$, each expression equals zero and no entropy change occurs.

Comparing these equations to equation $3.44,3.45$ and 3.46 for the polytropic process, it can be seen that the following equations would result:

$$
\begin{aligned}
& \frac{d P}{P}=-(1+i) \frac{d v}{v} \ldots \ldots \ldots \ldots \ldots \ldots \ldots \ldots \ldots \ldots .16 \\
& \frac{d P}{P}=\left(\frac{1+i}{i}\right) \frac{d T}{T} \\
& \frac{d T}{T}=-(i) \frac{d v}{v}
\end{aligned}
$$

Thus linking the three factors $\mathbf{P}, \mathbf{v}$ and $\mathbf{T}$ to the rate $\mathbf{i}$.

The above thermodynamic analysis, if accepted, indicates that the rate of return, yield and interest rates might might alter the elastic index $\boldsymbol{n}$ and have an impact in determining whether changes in the price level in an economy are reflected by changes in real productive content or by generation/absorption of entropic value. However, without empirical research, the above hypothesis cannot be tested. 


\section{Measurement of Value}

In both thermodynamic and economic systems, measurement of the values of variables is a field of research in itself, which this paper does not explore in depth. There are however some common threads.

In a thermodynamic system, only three primary properties are directly measurable - unit mass, length and time, and from these it is possible to measure volume, force and pressure. All other variables are derived at a secondary or tertiary level. Density is measured by mass per volume. A scale of temperature can be constructed by reference to the variation of volume of a fluid between two fixed points, for example the boiling and freezing points of water. Items such as the gas constant and entropy are more distantly estimated. The properties of real gases can depart from the model of an 'ideal' gas.

Similarly in an economic system, the same primary properties apply, though with different emphases. Volume is measured by reference to units with specific shape, form and use; price by reference to a single unit with specific shape, form and use set against a scale of money. $\mathbf{k}$ in a money system is a nominal value, defined as $£ 1, \$ 1,1 €$ etc. With varying degrees of accuracy it is possible to measure the number of money stock units $\mathbf{N}$. Velocity of circulation is thus assessable with reference to output at current prices. Measurement of a property such as entropy depends upon the degree to which changes in price levels can be split into those arising from real productive content and output, and those that do not. Items such as elasticity and utility are more distantly estimated. The properties of real economic systems are likely to depart from the notion of an 'ideal' economic system.

Thus in both disciplines, a few variables are easily quantifiable, but others are not. In each discipline participants are therefore forced to work mostly with the quantifiable variables to explain and derive the others.

In science, three items of information are required to specify a scale against which a variable is to be measured:

- A reference body to measure against

- The numbers attached to two or more standard points of such a scale

- The relationship between the variable to be measured and the particular property of the reference body, which is to be used to interpolate between the standard points.

In economics, value is not arrived at by such deterministic methods. It is determined in part by the confidence held in individual economies and currencies, with interest rates being the main lever on the money supply to hold prices at stable levels. It is determined by man-hours and the costs associated with the varieties of materials, energy and technologies inputted into products. It is also determined by entropic input, that is, value that cannot convert into real productive content during a particular process, i.e. speculation, scarcity or abundance. Thus value in economics is determined via circular, iterative processes, comparing individual prices and products with everything else, it is as much 'top-down' as 'bottom-up'.

It might be thought that a possible way round this problem is to base everything against an 'energy' scale, in the manner of 'emergy'. In recent years attempts have been made to calculate the energy content of some resources, but the problem with this approach is that it cannot take account of the relative entropic value that is embedded in price levels in an economy. Hau and Bakshi (2004) point also to problems arising from quantification, transformities and allocation between processes in relation to emergy.

It has been shown in this paper, that the internal value $\mathbf{U}$ of a product or factor of production can carry isentropic value as well as productive content, and accords with the view of Georgescu-Roegen (1979) that the entropy law is important. The reality is that money can only be set against other measures of value such as emergy if a monetary system can be constrained to operate isentropically, such that price always refers back to the nominal value $\mathbf{k}$.

Economics is essentially anthropocentric in nature rather than ecocentric, and the general replacement of money with emergy or some other scale entails also the populace getting to grips with the concept of entropy and ecocentric matters. The author does not regard this as practical.

\section{Summary and Conclusion}

In writing this paper the author has had to re-think some of his views first set out in his paper of 1982, more than twenty years ago, particularly in areas such as entropy value, productive content, cycle construction and growth. The thrust of this paper has been to lay out in detail, step by step, equivalent economic properties against each thermodynamic concept as applied to gases, though it is recognised that this approach might be seen as controversial. 
The starting point of the exposition, and by far the most important, was the introduction of the concepts of 'monetary carriers of value' and 'index of trading value'. These concepts enabled the construction of an ideal economic equation that matched the ideal gas equation for thermodynamic gas systems, and which suggested that value in an economic system might be equivalent to heat value in a thermodynamic system. Models constructed to meet the processes encountered in economic systems, such as money, shares and production all followed a similar pattern. This led to the belief that some credence could be attached to the results of applying thermodynamic laws to economic processes.

A number of economic processes were examined to obtain expressions for relationships between price, volume and the index of trading value, and entropy change. It was shown that the law of diminishing marginal utility matched a thermodynamic formula for marginal entropic value for an iso-trading process. The Le Chatelier Principle was employed to model the disequilibrium processes that govern the forward path of an economic system, and how capital, labour and resources are consumed to produce output. The algebraic logic led to output being expressed as an equation along the lines of a Cobb-Douglas function, but with an equilibrium constant and a free value disequilibrium function attached to it.

Following on from this an economic trade cycle was constructed, based a Joule cycle, and expressions were derived for the overall cycle efficiency, growth factor and entropic gain. It was shown that a cycle could be constructed which did not have an entropic gain, but it was recognised that the reality of economic systems and the laws of thermodynamics meant that such a position might be unlikely.

A simple money model was constructed to highlight the application of thermodynamic principles. It was very similar in construction to the well-known quantity theory, with velocity of circulation being equivalent to the index of trading value. The close nature of the comparison led to the belief that thermodynamic analysis for a polytropic case might yield a means of linking changes in price, output volume, money stock and velocity of circulation with the rate of return through the elastic index, though empirical research is needed to test the hypothesis of the comparison.

Last some thought was given to the measurement of value. The disciplines of thermodynamics and economics both rely on the ready measurement of only a few variables, with the rest being derived. Value in economic systems is composed of both real productive content and entropic value, and the application of a scale of energy, along the lines of emergy, will not by itself provide an answer to the problem of determining value, unless an economic system can be constrained to operate isentropically.

The conclusion that economic and thermodynamic theories may be linked is, in the author's view, born out to a certain degree by the analysis, but significant research in the future, at both theoretical and empirical levels, is required to add substance to the theory.

\section{References}

Bryant, J. (1982) 'A thermodynamic approach to economics', Energy Economics, Vol. 4, No. 1, pp.36-50.

Candeal, J.C. De Migule, J.R. Indurain, E. Mehta, G. B. (2001) 'Utility and entropy’, Economic Theory, SpringerVerlag, 17, pp.233-238.

Costanza R, Hannon B. 1989. Dealing with the mixed units problem in ecosystem network analysis. In: F Wulff, JG Field, KH Mann (eds) Network Analysis in Marine Ecology: Methods and Applications pp.90-115. Berlin: Springer.

Costanza R. 1980. Embodied energy and economic valuation. Science 210: 1219-24.

Georgescu-Roegen, N. (1971) 'The entropy law and the economic process', Harvard University Press, Cambridge, MA.

Georgescu-Roegen, N. (1979) ‘Energy analysis and economic valuation', Southern Economic Journal, 45, pp.10231958.

Goldberg, R.N. Tewari, Y.B. Bhat, T.N. (1993-1999) 'Thermodynamics of enzyme-catalysed reactions Parts 1 - 5', Journal of Physical and Chemical Reference Data. 
Hammond, G.P. (2004) 'Engineering sustainability: thermodynamics, energy systems and the environment', International Journal of Energy Research, 28, pp.613-639.

Hammond, G.P. \& Winnett, A.B. (2004) 'Some interdisciplinary perspectives on environmental appraisal and valuation', Towards an Environmental Research Agenda: A Third Selection of Papers', Palgrave MacMillan, Basingstoke, Ch.1, pp.3-33.

Hannon, B. (1973b) 'An energy standard of value'. Annals of the American Academy, 410: 139-153.

Hau, J.L. Bakshi, B.R. (2004) 'Promise and Problems of Emergy Analysis', Ecological Modelling, Ohio State University, Columbus, Ohio, 178: 215-225.

Kay, J. \& Schneider, E. (1992) 'Thermodynamics and measures of ecosystem integrity', Ecological Indicators', Elsevier, New York, pp.159-191.

Lisman, J. H. C. (1949) 'Econometrics statistics and thermodynamics'. Netherlands Postal and Telecommunications Services. The Hague, Holland Ch IV.

Odum, H T. (1971) 'Environment, power \& society’, Wiley, London.

Odum, H T. (1998). 'Emergy evaluation', International Workshop on Advance in Energy Studies, Porto Venere Italy.

Patterson, M. (1998) 'Commensuration and theories of value in ecological economics', Ecological Economics, 25 pp.105-125

Pikler, A. G. (1954) 'Optimum allocation in econometrics \& physics’, Weltwirtschaftliches Archiv.

Ruth, M. (1993) 'Integrating economics, ecology and thermodynamics'. Kluwer Academic, Dordecht

Samuelson, P. A. (1970) 'Maximum principles in analytical economics', Nobel Memorial Lecture. Massachusetts Institute of Technology, Cambridge, MA.

Samuelson, P. A. (1964) ‘An extension of the Le Chatelier principle’ Econometrica, 28, pp. 368-379.

Schneider, E. D. (1987) 'Schrödinger shortchanged'. Nature 328, 300.

Schneider, E. D. Kay J.J. (1995) 'Order from disorder: The thermodynamics of complexity in biology', What if life: The next fifty years. Reflections on the future of biology’, Cambridge University Press, pp.161-172.

Schrödinger, E. (1944) 'What is life?' London: Cambridge University Press.

Smith, E. Foley, D. K. (2002) 'Is utility theory so different from thermodynamics? Santa Fe Institute.

Smith, E. Foley, D. K. (2004) 'Classical thermodynamics and general equilibrium theory', Santa Fe Institute.

Soddy, F. (1934) 'The role of money', Routledge, London.

Söllner, F. (1997) 'A re-examination of the role of thermodynamics for environmental economics', Ecological Economics, 22, 175-201.

Sousa, T. Domingos, T. (2005) 'Is neoclassical microeconomics formally valid? An approach based on an analogy with equilibrium thermodynamics', Ecological Economics, in press, corrected proof available online. 